\title{
Fresnel-Green-Maxwell: a teoria da birrefringência em três atos
}

\author{
Fresnel-Green-Maxwell: the birefringence theory in three acts \\ Marcelo Costa de Lima*10, L.D.L. Freitas ${ }^{10}$ \\ ${ }^{1}$ Universidade Federal do Pará, Faculdade de Física, Belém, PA, Brasil.
}

Recebido em 06 de março de 2021. Revisado em 23 de abril de 2021. Aceito em 26 de abril de 2021.

\begin{abstract}
No presente artigo analisamos como as características básicas da teoria da birrefringência, conforme elaborada por Fresnel, sobreviveram inalteradas desde sua postulação, nos anos de 1820, sendo então confrontadas pelas teorias elastodinâmicas da luz, as quais ele próprio havia inspirado em suas especulações teóricas; para finalmente servir parcialmente de guia na construção da teoria eletromagnética da luz, chegando aos nossos dias com seus elementos basicamente inalterados.
\end{abstract}

Palavras-chave: éter luminífero, continuum elástico, elastodinâmica, meios anisotrópicos.

In the present article we analyze how the basic features of the theory of birefringence, as developed by Fresnel, survived unchanged since his postulation, in the 1820s, being then confronted by the elastodynamic theories of light, which he himself had inspired in his theoretical speculations; to finally serve partially as a guide in the construction of the electromagnetic theory of light, reaching our days with its elements basically unchanged.

Keywords: luminiferous ether, elastic continuum, elastodynamics, anisotropic media.

Neste ano de 2021 completam-se exatos 2 séculos desde que Augustin-Jean Fresnel (1788-1827) postulou a transversalidade da onda luminosa. Ao fazê-lo, redefiniu o sentido de polarização tirado dos emissionistas, incorporando esse conceito à teoria ondulatória da luz. Não aboliu o éter luminífero de Descartes e Huygens. Ao contrário, ampliou as possibilidades de sua intervenção, direta ou indireta, nos fenômenos físicos; dotando-o de características comparáveis às de um sólido elástico e inaugurando um dos mais férteis campos de investigação da física do século XIX. Impactou não somente o desenvolvimento da óptica, mas se espalhou por outros domínios como eletricidade e magnetismo. No centro deste debate vemos sua teoria ondulatória da birrefringência. Nesse trabalho rememoramos, celebramos e discutimos três momentos do desenvolvimento da teoria da birrefringência para polarizações fixas: sua formulação por Fresnel, sua expressão mecânica máxima, por Green, e sua ressignificação eletromagnética por Maxwell.

\section{Introdução}

Fresnel surgiu na cena científica da França no final das guerras napoleônicas. Adversário político declarado do Imperador, abandonou o seu posto de engenheiro do Corps des Ponts et Chaussées para resistir em armas

\footnotetext{
*Endereço de correspondência: mclima@ufpa.br
}

à "marcha dos 100 dias" em 1815. Viu-se momentaneamente em apuros com o fiasco que tal resistência representou, e a rápida acolhida de Napoleão pelo povo (e pelo exército) com o restabelecimento do Império Francês. Exilou-se na casa materna aguardando pelo pior. Lá começou a ocupar-se de experimentos de óptica, com pouco conhecimento do "estado da arte", àquela altura, mas sem dúvida alguma, em seu espírito, de que a luz tinha natureza ondulatória. Napoleão durou somente até a batalha de Waterloo e a sentença de Fresnel, pela insubordinação, nunca apareceu.

Fresnel chegou a Paris em março de 1816, trazendo consigo uma redação revisada de suas investigações sobre a difração, logo publicada nos Annales de Physique [1] de François Arago (1786-1853); de quem se tornou colaborador e protégé. Inteirou-se rapidamente das novidades no campo da óptica, notadamente a descoberta do princípio da interferência por Thomas Young (1773-1829) [2 4, em 1801, a da polarização da luz por Etienne-Louis Malus (1775-1812) [5-10], em 1809, e da polarização cromática por Arago [11], em 1810. A primeira, uma trincheira isolada dos defensores da natureza ondulatória da luz. A segunda e a terceira, território dos emissionistas cujo vigor fora renovado pela descoberta de Malus. Embora tenha se ocupado da polarização já em seus primeiros experimentos, Fresnel foi mais propositivo no campo da difração, visto por ele como terreno fértil para o avanço da teoria ondulatória da luz. A culminância desses esforços deu-se com a sua conquista do prêmio da academia de ciências, para o 
ano de 1819, com sua memória "Sur la diffraction de la lumiére" [12, de caráter ondulatório. Restava agora tomar dos emissionistas a primazia sobre a polarização da luz, nas palavras de Silliman [13] "o mais sério desafio para a concepção ondulatória."

A noção de polarização herdada por Fresnel era de que se tratava de uma propriedade das partículas luminais, as quais adquiriam "polos" ao atravessarem o meio anisotrópico, estando os raios emergentes polarizados. Era igualmente concebível que tais polos fossem preexistentes nas partículas da luz comum, numa mistura aleatória, e o meio cristalino apenas as selecionava, encaminhandoas em direções distintas conforme sua orientação polar, em planos de polarização mutuamente ortogonais um ao outro. Assim se explicava a birrefringência em cristais como o Espato da Islândia, na qual surgiam os raios ordinário e extraordinário, como Christiaan Huygens (1629-1695) os chamara [14, mais de cem anos antes, seguindo Erasmus Bartholin (1625-1698) que fora seu descobridor em 1669. Malus descobrira em 1809 que se tratava de uma condição que se podia produzir por reflexão [5] da luz comum, segundo um ângulo adequado, prescindindo, portanto, do meio cristalino e evidenciando que este tinha um papel seletor. Também a polarização cromática, descoberta por Arago [11] em 1810, e que consiste na produção de cores pela luz branca polarizada ao atravessar finas lâminas cristalinas, rapidamente fora incorporada ao quadro teórico dos emissionistas, com a chamada teoria das polarizações móveis de Jean-Baptiste Biot (1774-1862) [15-19].

A presença de cores nos fenômenos de polarização cromática levou Young à suspeita da interveniência do seu princípio da interferência operando em meio à birrefringência no interior da lâmina cristalina [20] Fresnel logo endossou a ideia, mas sabia de suas próprias investigações, parte delas sugeridas por Arago, que os raios ordinário e extraordinário, produzidos na birrefringência, não eram capazes de produzir padrões de interferência 21. Da discussão destes resultados negativos com Andrè-Marie Ampère (1775-1836) surgiu da parte deste a sugestão da transversalidade da onda luminosa: os raios ordinário e extraordinário não produziriam interferência por corresponderem a oscilações em direções independentes. Fresnel, entretanto, abandonou provisoriamente a ideia, havendo "tentado em vão explicar os fenômenos com essas hipóteses". Em janeiro de 1817 Arago debateu o tema da não interferência dos raios da birrefringência com Young, que considerou a possibilidade de uma transversalidade parcial e pequena, mostrando-se cético que ela pudesse ser o elemento responsável por efeitos tão sensíveis. Em setembro do mesmo ano, ao redigir o verbete Cromática para a Enciclopédia Britânica, Young voltou a considerar a possibilidade do pequeno componente transversal da onda luminosa em conexão com os fenômenos da polarização, para novamente considerar improvável como hipótese física, embora talvez útil, como hipótese matemática 22]. Permanecia assim preso à ideia de que a luz seria algo similar à onda acústica. Interpretações físicas a parte, ambos Fresnel e Arago acreditavam haver reunido sólida evidência fenomenológica da não interferência dos raios ordinário e extraordinário, o que culminou no artigo "Sur l'Action que les rayons de lumière polarisés exercent les uns sur les autre" [23] em coautoria. Nele uma série de experimentos são minuciosamente descritos, mas nenhuma nota ou especulação sobre sua interpretação baseada na hipótese da transversalidade é levantada, por não representar o pensamento de Arago.

Fresnel, entretanto, sentia-se maduro para aceitar a transversalidade completa da luz, o que fez no caderno de julho de 1821 dos Annales de Physique [24] em suas "Considerations mécaniques sur la polarisation de la lumiére" (p. 179), defendendo a necessidade da transversalidade da onda luminosa e discutindo a inadequação do éter fluido de Huygens e seus antecessores, esboçando a estrutura do éter necessária para suportar tais vibrações. É o nascimento do éter do tipo sólido elástico. Com essa ressignificação da onda luminosa, visava atacar de frente os dois últimos redutos da óptica emissionista, construindo uma teoria ondulatória da birrefringência, que pudesse rivalizar e mesmo superar a teoria da birrefringência de Malus (das polarizações fixas) e teoria das polarizações móveis de Biot. A descrição destes embates, particularmente os travados com Biot, foge ao escopo deste trabalho; ao que recomendamos a leitura de Buchwald [25]. Diremos apenas que o sucesso de Fresnel removeu o último grande obstáculo à teoria ondulatória da luz, assegurando o predomínio dessa pelo restante do século XIX, até a introdução da natureza dual da luz em 1905, com o nascimento do fóton.

\section{Primeiro Ato: Fresnel}

A teoria ondulatória da birrefringência remontava a Huygens, mas naquele começo da década de 1820 o ambiente lhe parecia desfavorável devido descoberta dos cristais biaxiais por David Brewster (1781-1868), em 1818. Brewster estabeleceu a relação entre propriedades ópticas e cristalográficas destes materiais, apontando a não aplicabilidade da teoria da birrefringência de Huygens para além do Espato da Islândia [26]. Estudou mais de uma centena de cristais, configurando de forma inequívoca a presença de dois ou mais "eixos de dupla refração" como regra e não como exceção. Em uma de suas tabelas listou duas dezenas de cristais de um só eixo (a partir daí ditos uniaxiais), entre eles o quartzo e o "calcareous spar" (calcita). Entre os biaxiais identificou a mica, a aragonita (que é, como a calcita, uma variedade do carbonato de cálcio) e o carbonato de potássio.

Assim, Fresnel tomou a formulação de Huygens (para cristais uniaxiais) como ponto de partida, ciente da necessidade de um esquema mais abrangente que devia recuperá-la como caso particular. Huygens argumentara no Traité de la Lumière (1690) que um dos raios da 
birrefringência no Espato da Islândia sofre a refração conforme a lei de Snell, propagando-se dentro do cristal com uma velocidade que independente da orientação da propagação em relação ao eixo óptico, daí tê-lo chamado "ordinário". Já o extraordinário não obedece à lei de Snell, o que indica uma velocidade variável no meio, dependente da direção de propagação em relação à direção do eixo óptico. Para explicar a formação dos dois raios, Huygens propôs uma versão modificada do princípio que hoje leva seu nome, admitindo que cada ponto da frente de onda era fonte de dois tipos de ondas secundárias, uma esférica (como na versão usual do princípio de Huygens) e outra esferoidal. As envoltórias dessas duas classes de ondas secundárias constituem as frentes de onda, num tempo posterior, dos raios da dupla refração, correspondentes a um distúrbio originado em um ponto dado, num tempo anterior. Há aqui uma dificuldade conceitual que não escapara a Huygens: na medida em que concebia a luz como pulsos longitudinais, não havia atributo físico da onda que permitisse justificar, em bases físicas, a razão pela qual o princípio de Huygens devia ser adotado na versão modificada, o que levou a hipótese de "dois éteres" no interior do cristal. Embaraços conceituais a parte, fato é que da aplicação desse princípio de Huygens modificado se pode deduzir expressões analíticas para as velocidades dos raios ordinário e extraordinário, a então chamada Lei de Huygens da birrefringência. As velocidades dos raios ordinário $(o)$ e extraordinário $(e)$ são dadas por

$$
v_{o}^{2}=a^{2}, \quad v_{e}^{2}(\theta)=a^{2} \cos ^{2} \theta+c^{2} \operatorname{sen}^{2} \theta,
$$

em que $\theta$ é o ângulo que a direção da normal à frente de onda, em um dado ponto, faz com a direção do eixo óptico do cristal (uniaxial). As constantes $a$ e $c$ são os semieixos do esferoide de Huygens. No caso do Espato da Islândia, a é o semieixo menor. Assim, a velocidade do raio extraordinário é sempre maior ou igual a do raio ordinário, o que caracteriza os cristais ditos negativos.

Fresnel remodelou a construção original de Huygens, para obtenção das velocidades dos raios ordinário e extraordinário, considerando a propagação de ondas planas, no interior do cristal uniaxial. A distinção entre as velocidades associadas à onda plana do raio-o e do raio-e foi por ele atribuída ao novo significado de polarização que adotou, como os dois possíveis modos de vibração independentes sobre a frente de onda. Fresnel concebeu o cristal uniaxial como meio elástico que reage às deformações, paralela e perpendicular ao eixo óptico, com forças restauradoras distintas e, por isso, anisotrópico. Assim, uma deformação elástica ocorrendo perpendicularmente ao eixo óptico sofreria força restauradora diferente daquela sofrida por uma deformação ocorrendo paralelamente ao eixo óptico. Dependendo, então, da direção de vibração transportada pela onda plana no cristal, a mesma "enxerga" a anisotropia do meio de forma diferente [24]. Modos de vibração distintos, associados à esforços elásticos distintos, igualmente se converteriam em "vis vivas" $\left(v^{2}\right)$ distintas, o que explicaria as formas distintas observadas em (1). Fresnel associou ao raio-o o modo de polarização perpendicular ao eixo e, por isso, dotado de uma velocidade que independe da orientação em relação a ele [24, p. 186], já que assumira que a força restauradora é sempre a mesma perpendicularmente ao eixo. Para o raio-e admitiu que a vibração ocorria no próprio plano da seção principal, razão pela qual sua velocidade depende da orientação relativamente ao eixo, já que envolve a ação de forças restauradoras distintas, perpendicular e paralela ao eixo. Ilustramos a situação na Figura 1.

Para Huygens um ponto na frente de onda gera dois tipos de ondas secundárias (o princípio de Huygens modificado): uma esférica e a outra esferoidal. Assim as
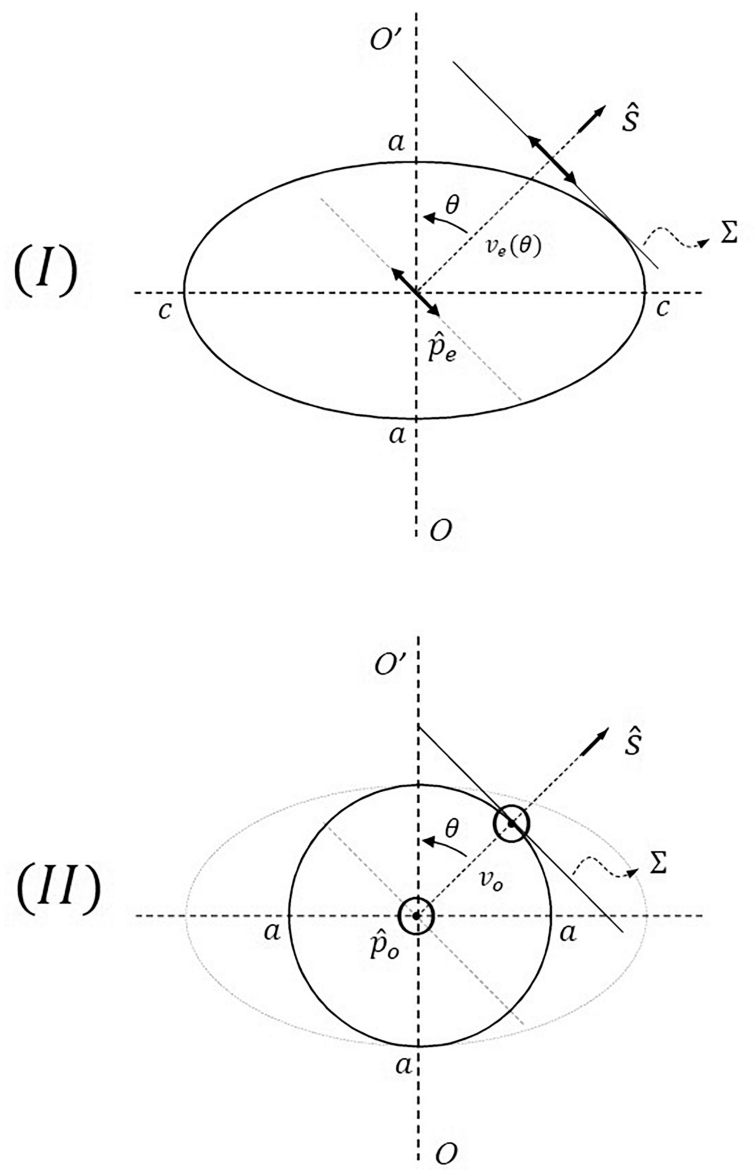

Figura 1: A construção de Fresnel para a Lei de Huygens: em (I) a frente de onda plana $\Sigma$, de normal $\hat{s}(\theta)$, associada ao raio extraordinário, a qual originou-se do distúrbio no centro da figura em $t=0$, tangencia o elipsoide de Huygens em $t=1$. $\mathrm{O}$ modo vibra na seção principal do cristal (plano da página), na direção $\hat{p}_{e}$. Em decorrência disso, sua velocidade de fase depende do ângulo $\theta$, formado com o eixo óptico $O O^{\prime}$, variando entre os limites $a<v_{e}<c$. Em (II) vê-se a frente de onda associada raio ordinário, cuja vibração se dá na direção $\hat{p}_{o}$ perpendicular à mesma seção principal do cristal (saindo da página). Por tratarse de um distúrbio ocorrendo fora do plano da seção principal, sua velocidade de fase independe do ângulo formado com o eixo $O O^{\prime}$, sendo $v_{o}=a$. 
superfícies de Huygens, associadas ao problema, podem ser definidas comd 1

$$
r^{2}=a^{2}
$$

e o elipsoide de Huygens

$$
H_{i j} x^{i} x^{j}=1
$$

em que

$$
\mathbf{H}=\left(\begin{array}{ccc}
c^{-2} & 0 & 0 \\
0 & c^{-2} & 0 \\
0 & 0 & a^{-2}
\end{array}\right)
$$

e $\left\{x^{i}, i=1,2,3\right\} \equiv(x, y, z)$ são coordenadas cartesianas, centradas na origem da Figura (1), com o eixo $z$ na direção do eixo óptico e os eixos $x, y$ tomados sobre a seção circular do elipsoide de revolução.

Se introduzimos coordenadas esféricas, centradas na mesma origem, o versor normal à onda, $\hat{s}$, na Figura (1), corresponderá ao vetor radial unitário, da base local associada a este sistema de coordenadas, isto é,

$$
\hat{s}=\left(\begin{array}{c}
\operatorname{sen} \theta \cos \varphi \\
\operatorname{sen} \theta \operatorname{sen} \varphi \\
\cos \theta
\end{array}\right) .
$$

Os versores das direções das polarizações ordinária, $\hat{p}_{o}$, e extraordinária, $\hat{p}_{e}$, podem ser, por sua vez, caracterizados como os versores azimutal e polar, respectivamente, também associados à base local das coordenadas esféricas, a saber ${ }^{2}$

$$
\hat{p}_{o}=\left(\begin{array}{c}
-\operatorname{sen} \varphi \\
\cos \varphi \\
0
\end{array}\right), \quad \hat{p}_{e}=\left(\begin{array}{c}
\cos \theta \cos \varphi \\
\cos \theta \operatorname{sen} \varphi \\
-\operatorname{sen} \theta
\end{array}\right)
$$

Como afirmamos é a distinção física dos modos de vibração das ondas planas associadas aos raios $o$ e $e$ que determinará suas distintas velocidades. Se introduzimos a matriz

$$
\mathbf{K}=\left(\begin{array}{ccc}
a^{2} & 0 & 0 \\
0 & a^{2} & 0 \\
0 & 0 & c^{2}
\end{array}\right)
$$

é possível calcular as velocidades (1) de ambos os modos de polarização $(\hat{p})$, ordinário e extraordinário, a partir de uma prescrição única:

$$
v^{2}(\hat{p}):=K_{i j} p^{i} p^{j} .
$$

\footnotetext{
1 Aqui, e por todo o artigo, adotaremos notação matemática anacrônica, ora indicial, ora vetorial, conforme a conveniência. Ao adotarmos notação indicial, igualmente adotamos a chamada "convenção da soma": índices repetidos em uma mesma expressão indicial, subentende-se que há uma soma sobre todos os valores do índice. Assim, por exemplo, $H_{i j} x^{j}=H_{i 1} x^{1}+H_{i 2} x^{2}+H_{i 3} x^{3}$. O uso de índices acima e abaixo, denota serem esses contravariantes e covariantes, respectivamente, embora tal distinção seja irrelevante em um sistema cartesiano.

${ }^{2}$ Nos afastamos aqui da dedução de Fresnel, que caracterizou as direções das polarizações por cossenos diretores. Mas isso não nos afasta, em essência, de sua linha de raciocínio.
}

Fresnel chamou (8) de equação da elasticidade 27]. Isso o levou à conjectura de que a generalização para a birrefringência biaxial consistia em admitir-se que, nesses cristais, a matriz $\mathbf{K}$, tem a forma diagonal

$$
\mathbf{K} \equiv\left(\begin{array}{ccc}
a^{2} & 0 & 0 \\
0 & b^{2} & 0 \\
0 & 0 & c^{2}
\end{array}\right)
$$

tomando-se os eixos cartesianos coincidentes com os eixos de elasticidade [27]. A consequência imediata desta generalização é que, de acordo com (8), nenhum modo de polarização terá sua velocidade independente da direção de propagação no cristal biaxial. Este fato, primeiramente reconhecido por Fresnel [28], implica em dizer que no cristal biaxial não há, a rigor, raios ordinários.

\subsection{As polarizações como problema de autovalor}

No que segue faremos uma construção matemática anacrônica, necessária à unidade formal do presente artigo, tal e qual faremos nos dois outros momentos históricos que serão abordados. Dado que (9) desempenha o papel central na caracterização da elasticidade do cristal biaxial, quer-se exibir $(\hat{p}, v)$ uma vez conhecidas as elasticidades principais e a normal à onda $(\mathbf{K}, \hat{s})$. Seguindo Fresnel fazemos as imposições:

1. A onda é puramente transversal

$$
p^{i} s_{i}=0 \text {. }
$$

2. Os estados de polarização, $\hat{p}$, são direções que extremizam $v$. Assim, conforme (8),

$$
K_{i j} p^{i} d p^{j}=0
$$

Da primeira imposição e do fato de que $\hat{p}$ é, por construção, normalizado, resulta que,

$$
d p^{i} s_{i}=0, \quad p^{i} d p_{i}=0,
$$

Tais condições tomadas conjuntamente equivalem a dizer que os vetores $\left(s^{i}, p^{i}, d p^{i}\right)$ formam uma tríade mutuamente ortogonal. Assim, uma forma equivalente de (11) pode ser

$$
K_{i j} p^{i}(\hat{s} \times \hat{p})^{j}=0 .
$$

Ainda, de 11 vê-se que o vetor $K_{i j} p^{j}$ pertence ao plano gerado por $\hat{s}$ e $\hat{p}$, o que nos permite escrever

$$
K_{i j} p^{j}=\alpha s_{i}+\beta p_{i} .
$$

Os coeficientes $(\alpha, \beta)$ são fixados projetando-se a equação alternativamente em $\hat{s}$ e $\hat{p}$, no que resulta, em conformidade com (8),

$$
\alpha=K_{i j} p^{j} s^{i}, \quad \beta=v^{2} .
$$


Retornando à 14, com os coeficientes assim determinados, chega-se à equação de autovalor para os autoestados de polarização, $\hat{p}$, associados a uma direção $\hat{s}$, a saber,

$$
O^{i j}(\hat{s}) K_{j a} p^{a}=v^{2} p^{i}
$$

em que

$$
O^{i j}(\hat{s}):=\delta^{i j}-s^{i} s^{j}
$$

foi introduzido por conveniência. 3

A equação secular associada,

$$
\operatorname{det}\left[\mathbf{O}(\hat{s}) \mathbf{K}-v^{2} \mathbf{I}_{3}\right]=0
$$

fornece a equação das normais de Fresnel. Tal equação pode ser igualmente escrita na forma equivalente

$$
\frac{s_{x}^{2}}{a^{2}-v^{2}}+\frac{s_{y}^{2}}{b^{2}-v^{2}}+\frac{s_{z}^{2}}{c^{2}-v^{2}}=0 .
$$

\subsection{As superfícies definidas por Fresnel}

Em sua caracterização da birrefringência Fresnel enfatizou construções geométricas apresentando a síntese de sua teoria da birrefringência através de superfícies.

Primeiramente,

$$
K_{i j} x^{i} x^{j}=1
$$

o elipsoide de elasticidade $4^{4}$. No sistema cartesiano coincidente com os eixos de elasticidade esse se escreve como

$$
a^{2} x^{2}+b^{2} y^{2}+c^{2} z^{2}=1
$$

A interseção do elipsoide de elasticidade pelo plano $\Sigma$, de normal $\hat{s}$, conforme ilustrado na Figura (2) produz uma elipse. Como é sabido da geometria analítica existem duas possíveis direções de $\hat{s}$ para as quais a mesma degenera em círculo. Tais direções são os eixos ópticos do cristal (biaxial). Se, no entanto, o elipsoide 19 é de revolução, sabe-se também da geometria analítica que as duas seções circulares degeneram em uma só, quando então seus eixos normais definem uma só direção, o eixo óptico do cristal uniaxial.

Se agora associamos vetores posição $x^{i}:=v p^{i}$, a cada polarização, $p^{i}$, cujo módulo é sua correspondente

\footnotetext{
3 A matriz $O^{i j}(\hat{s})$ é um operador que projeta os objetos, sobre os quais atua, no plano $\Sigma$ ortogonal à $\hat{s}$. Assim, por exemplo, se constata facilmente que $O_{i j} s^{j}=0$, e que $O_{i j} p^{j}=p_{i}$, conforme o esperado, tendo-se em conta que $\hat{s}$ não tem projeção ortogonal a si mesmo e que $\hat{p}$ pertence ao plano $\Sigma$. Também, $O^{i b} K_{b j}$ é uma projeção da matriz $K_{b j}$ no plano $\Sigma$. Como todo projetor é idempotente, $O_{i j} O^{j k}=O_{i}^{k}$, por construção, como se constata facilmente da definição.

${ }^{4} \mathrm{Na}$ nomenclatura de hoje, o elipsoide de índices ou indicatriz óptica 29.
}

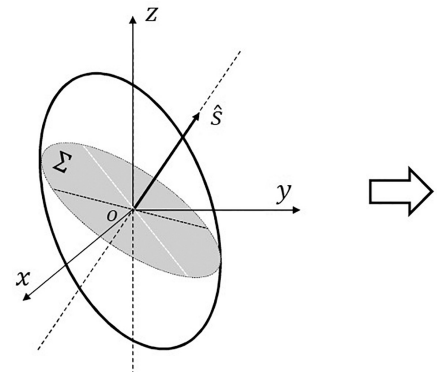

(I)

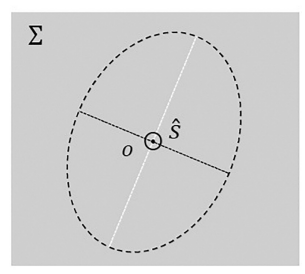

(II)
Figura 2: (I) Elipsoide de elasticidade seccionado pelo plano $\Sigma$ de normal $\hat{s}$. (II) Seção elíptica, no plano $\Sigma$.

velocidade, $v$, chegamos, a partir de (8), à superfície quártica

$$
\left(K_{i j}-\delta_{i j} r^{2}\right) x^{i} x^{j}=0
$$

a qual Fresnel chamou superfície de elasticidade. No sistema cartesiano coincidente com os eixos de elasticidade isso equivale a

$$
a^{2} x^{2}+b^{2} y^{2}+c^{2} z^{2}-\left(x^{2}+y^{2}+z^{2}\right)^{2}=0,
$$

Se alternativamente associamos vetores posição $x^{i}:=$ $v s^{i}$, à direção $s^{i}$, haverá duas possibilidades para $v$ as quais são os autovalores dos dois modos de polarização associados à direção $\hat{s}$. Substituindo-o em (17) temos então o lugar geométrico,

$$
\operatorname{det}\left[\mathbf{O}(\hat{r}) \mathbf{K}-r^{2} \mathbf{I}_{3}\right]=0,
$$

em que a matriz $\mathbf{O}(\hat{r})$ é definida como

$$
\mathbf{O}(\hat{r}): O^{i j}=\delta^{i j}-\frac{x^{i}}{r} \frac{x^{j}}{r},
$$

a superfície normal de Fresnel, do sexto grau.

No sistema de eixos cartesianos coincidentes com os eixos de elasticidade, (23) pode igualmente ser escrita como

$$
\frac{x^{2}}{a^{2}-r^{2}}+\frac{y^{2}}{b^{2}-r^{2}}+\frac{z^{2}}{c^{2}-r^{2}}=0 .
$$

Finalmente definiu a superfície de onda 5

$$
\operatorname{det}\left[\mathbf{K}-r^{2} \mathbf{O}(\hat{r})\right]=0,
$$

a qual define o lugar geométrico em que se encontram, após um intervalo de tempo unitário, os distúrbios originados de um dado distúrbio original, no instante inicial. No sistema de eixos cartesianos coincidentes com os eixos de elasticidade, uma forma equivalente de (26) é

$$
\frac{a^{2} x^{2}}{a^{2}-r^{2}}+\frac{b^{2} y^{2}}{b^{2}-r^{2}}+\frac{c^{2} z^{2}}{c^{2}-r^{2}}=0 .
$$

\footnotetext{
${ }^{5} \mathrm{Na}$ nomenclatura corrente superfície de raio 29 .
} 
Se a matriz $\mathbf{K}$ tem a forma degenerada (7), como nos cristais uniaxiais, a equação da onda pode ser fatorada no produto

$$
\left(r^{2}-a^{2}\right)\left(H_{i j} x^{i} x^{j}-1\right)=0
$$

que tem como solução as superfícies do princípio de Huygens modificado (2) e (3).

Os obstáculos, avanços e revezes, enfrentados por Fresnel na construção de tais superfícies foram recuperados para a história da ciência graças ao resgate de manuscritos não publicados à época, compilados e publicados por Émile Verdet e Léonor Fresnel nas Oeuvres Complètes 30 33 de Fresnel. Isso permitiu que não somente ao próprio Verdet [34, 35], mas também historiadores como Buchwald [25] e Darrigol [36] lançassem luzes sobre a gênese da teoria da birrefringência.

O que foi dito acima se refere à obtenção das chamadas polarizações fixas, tal como Biot as chamava. $\mathrm{Na}$ teoria emissionista, das polarizações móveis, outras modalidades de polarização das partículas luminais eram a polarização oscilante e a polarização rotatória [15, às quais estavam associadas aos fenômenos de polarização cromática e a "peculiar birrefringência" apresentada pelo quartzo ao longo de seu eixo óptico. Fresnel produziu o equivalente ondulatório da teoria das polarizações móveis, na verdade superando-a, ao demonstrar que a produção de cores, nos fenômenos de polarização cromática, resulta do princípio da interferência, de Young, condicionado a operar somente sobre raios de mesma polarização. A sucessiva decomposição do raio incidente no cristal birrefringente e no analisador (também birrefringente), produzia novos raios capazes de interferir dois a dois. $O$ caso da birrefringência no quartzo o levou à introduzir polarização circular [37, estado em que o vetor polarização $\hat{p}$ é decomposto em duas outras polarizações $\hat{p}_{ \pm}$, as quais giram simultaneamente sobre a frente de onda, uma em sentido horário $(+)$ e a outra em sentido anti-horário (-). Fresnel então introduziu a nomenclatura de polarização linear, circular (à esquerda e à direita) e elíptica (à esquerda e à direita), ainda adotada. Concluiu assim a "unificação final" [25, p. 260] de suas contribuições à óptica.

\subsection{A fundamentação elastostática}

Fresnel postulou a transversalidade da onda luminosa e construiu com ela sua teoria da birrefringência, guiado por extraordinária intuição e imersão profunda nos fenômenos os quais buscava dar uma representação matemática no contexto da hipótese ondulatória. Vistas assim tais contribuições representam uma possível descrição ondulatória da luz em perfeito acordo com a experiência. Na redação final de seus artigos publicados à época, particularmente a "Mémoire" 38, ele parece se esforçar para convencer o leitor de que tudo decorre, naturalmente, da dinâmica de um meio elástico que somente é capaz de propagar ondas transversais, o qual responde às deformações elásticas com forças restauradoras anisotrópicas no interior do cristal.

Era preciso então assumir que o éter luminífero não só fosse capaz de impor resistência à deformações sobre a frente de onda, mas ainda que fosse infinitamente rígido à compressão/descompressão de duas frentes de onda adjacentes quaisquer. A existência de ondas transversais somente seria concebível em um éter com estrutura similar à de um sólido elástico, pois no éter fluido de Huygens, Young e Arago somente ondas longitudinais, podiam ser concebidas. A luz era a "onda sonora" no éter da "velha escola". Esse grau de ruptura com as concepções herdadas levou Darrigol [36, p. 214] a qualificar 1821 como o "annus mirabilis" na obra científica de Fresnel.

Assim, argumentou Fresnel, o meio elástico responde à deformação elástica unitária $\hat{p}$ produzida pela passagem da luz, em um ponto do mesmo, com força elástica restauradora,

$$
F_{i} \propto K_{i j} p^{j}
$$

o que é a expressão da lei de Hooke, porém anisotrópica. Daí serem diferentes as velocidades de propagação para diferentes polarizações, pois são diferentes tempos de resposta do meio, em um mesmo ponto, para diferentes direções de deformação. A força elástica na direção da deformação é então

$$
F_{i} p^{i} \propto K_{i j} p^{i} p^{j}
$$

Há, porém, direções para as quais a força é colinear com o deslocamento, isto é,

$$
F_{i} \propto v^{2} p_{i}
$$

quando então ocorrerá que

$$
v^{2}=K_{i j} p^{i} p^{j}
$$

Assim, a equação da elasticidade, (8) bem como a superfície de elasticidade 21) adquirem, nesse contexto, não somente um significado geométrico, mas também mecânico.

Uma teoria matemática da dispersão da luz talvez fosse a última contribuição de Fresnel ao campo da óptica, não fosse a tuberculose ter-lhe abreviado a vida, aos 39 anos, em 1827. Mas sabemos que havia começado à esboçá-la, a começar por cunhar o termo "dispersão" [34, p. xcv] [39, p. 89] para designar o fato de que raios de cores distintas são refratados em direções distintas, ao penetrarem em um mesmo meio transparente, homogêneo e isotrópico. Apontou que isso equivalia a dizer que raios de diferentes comprimentos de onda propagavam-se com diferentes velocidades. Para explicar o fenômeno imaginou que o raio de ação das forças elásticas, que definem a velocidade de propagação da luz no meio, não fosse infinitamente pequeno, mas de 
tal ordem que pudesse apresentar sensibilidades distintas aos distintos comprimentos de onda; mais eficientes em atrasar ondas curtas do que as longas e, por consequência, sendo as curtas mais refratadas que as longas.

A formulação mecânica incipiente, da parte de Fresnel, colocou em pauta a necessidade do desenvolvimento de uma dinâmica do contínuo elástico, campo que experimentou rápido desenvolvimento a partir de 1820. É difícil imaginar que as concepções de Fresnel acerca do éter luminífero não tenham relação direta com esse fato.

\subsection{O desenvolvimento da elastodinâmica}

Com efeito, em maio de 1821, Claude Louis Marie Henri Navier (1785-1836) comunicou à academia de ciências de Paris, uma equação de onda para as deformações no interior de um sólido elástico [40]. Considerou o meio elástico como conjunto de uma infinidade de partículas, agindo umas sobre as outras por forças atuantes segundo as linhas que as une. Disso resultou um meio isotrópico caracterizado por uma só constante elástica, a qual nomeou $\varepsilon$. A equação obtida por Navier, em notação atual, tem a forma

$$
\rho \frac{\partial^{2} \vec{e}}{\partial t^{2}}=\varepsilon\left[2 \nabla(\nabla \cdot \vec{e})+\nabla^{2} \vec{e}\right]
$$

sendo $\vec{e}$ o vetor deslocamento da partícula com relação a sua posição de equilíbrio.

Augustin-Louis Cauchy (1789-1857) assumiu então grande protagonismo no desenvolvimento deste campo de investigação. Em 1827 publicou "De la Pression ou Tension dans un corps solide" [41] no qual introduziu o conjunto de coeficientes das tensõe ${ }^{6}\left\{T_{i j}\right\}$ bem como o vetor tensão $\left\{t^{i}\right\}$ e a relação deste último com o primeiro. Em notação anacrônica

$$
t^{i}(\hat{s})=T^{i j} s_{j}
$$

em que $\hat{s}$ é o versor normal à superfície em que a tensão é exercida. Cauchy, entretanto, creditou a relação acima aos estudos de Fresnel sobre birrefringência [41, p. 59]. $\mathrm{O}$ vetor tensão, por sua vez, dava origem tanto à pressão normal $(P)$ quanto a tensão cisalhante $(t)$, definidas como

$$
P(\hat{s}):=T^{i j} s_{i} s_{j}, \quad t(\hat{s}, \hat{p}):=T^{i j} s_{j} p_{i}
$$

em que $\hat{p}$ é qualquer direção sobre a superfície em questão $(\hat{s} \cdot \hat{p}=0)$, havendo portanto duas tensões cisalhantes independentes.

Em 1828 Cauchy apresentou-nos a extensão ao contínuo elástico da Lei de Hooke [42, na forma de uma relação entre as tensões $\left\{T_{i j}\right\}$ e as deformações $\left\{e_{i j}\right\}$. Mostrou que o meio isotrópico poderia ser capaz de resistir diferentemente à compressão e a distorção, associando uma constante elástica à cada tipo de deformação, às

\footnotetext{
${ }^{6}$ Hoje tensor de tensões.
}

quais nomeou respectivamente $(k, K)$. Disso resultou, em notação anacrônica

$$
T_{i j}:=k e_{i j}+K \nabla \cdot \vec{e} \delta_{i j}
$$

sendo que 7

$$
e_{i j}:=\frac{1}{2}\left(\partial_{j} e_{i}+\partial_{i} e_{j}\right)
$$

são as deformações 8 sendo $\left\{e^{i}, i=1,2,3\right\}$ os componentes do vetor deformação no ponto em questão do contínuo elástico. Também em 1828 Cauchy publicou uma teoria geral da elasticidade em meios anisotrópicos 43, partindo de uma abordagem "molecular", que herdara de Navier, introduzindo a anisotropia como resultado de uma aglomeração diferenciada das moléculas nas diferentes direções. Introduziu inicialmente 21 coeficientes elásticos $\left\{\bar{C}_{i j k l}\right\}$, dos quais 6 dependiam da condição inicial da tensão. Ao assumir a condição inicial nula da tensão restavam 15 coeficientes, para então reduzi-los à 2 no caso isotrópico [44]. Por outro lado, mantendo a tensão inicial e fazendo imposições de simetria por inversão dos eixos cartesianos chegou a 9 coeficientes elásticos, na verdade eram coeficientes por unidade de densidade $(\rho)$, os quais designou por $(G, H, I ; L, M, N ; P, Q, R)$, generalizando a lei de Hooke na forma

$$
T^{i j}:=\rho \bar{C}^{i j k l} e_{k l}
$$

Disso pode obter a dinâmica das deformações elásticas a partir, conjuntamente, da lei de Hooke generalizada e das leis de Newton, no que resultou

$$
\frac{\partial^{2} e^{i}}{\partial t^{2}}=\bar{C}^{i j k l} \partial_{k} \partial_{l} e_{j}
$$

em que $(G, H, I ; L, M, N ; P, Q, R)$ são os graus de liberdade independentes dos coeficientes $\left\{\bar{C}_{i j k l}\right\}$.

Os autores que promoveram o desenvolvimento da teoria elástica da luz, a partir dos anos de 1830, caracterizaram o surgimento das tensões elásticas em resposta ao deslocamento relativo das partículas constituintes no meio, fato esse representado acima pela presença de $\partial e^{i} / \partial x^{j}$ na formulação da lei de Hooke, seja em 30 ou 32. Além de Cauchy, assim o fizeram Franz Ernst Neumann (1798-1895) [45], James MacCullagh (18091847) [46, 47] ou George Green (1793-1841) [48, 49]. Nisso diferiram todos de Fresnel, que considerou o deslocamento absoluto $e^{i}$, em seu esboço de uma fundamentação dinâmica da birrefringência no período prévio à teoria elástica dos sólidos.

Em 1830 Cauchy tratou da óptica em meios cristalinos, tomando como base sua teoria elástica

\footnotetext{
7 Usaremos sempre que convir a notação compacta $\left\{\partial_{i}, i=\right.$ $1,2,3\}$ como uma abreviação às derivadas parciais relativamente às coordenadas $\left\{x^{i}, i=1,2,3\right\}$. Assim, $\partial_{i} \equiv \partial / \partial x^{i}$.

8 Hoje tensor deformação.
} 
de 1828 aplicada ao éter luminífero [50]. Logo se deparou com uma ambiguidade que se revelaria crônica na elastodinâmica da luz, a saber, as duas maneiras alternativas de se fixar a direção de vibração da luz polarizada: perpendicular ao plano de polarização (como Fresnel) ou paralela ao plano de polarização. Naquela que ficou conhecida como $1^{\underline{a}}$ teoria da Cauchy da óptica cristalina, adotou a segunda prescrição, apresentando sua primeira dedução das leis da birrefringência. Seus resultados não diferem daqueles obtidos independentemente, em 1832, por Neumann 44. Quando aplicada ao meio isotrópico, essa teoria enfrentou dificuldades ao tratar da lei da reflexão/refração da luz plano polarizada, predizendo as leis de Fresnel, dos senos e das tangentes, de forma inversa, para o raio incidente polarizado paralelamente ou perpendicularmente ao plano de incidência. Também as condições de contorno na interface foram adotadas "ad hoc" e careciam de justificativas mecânicas claras [51. Como decorrência, Cauchy reformulou sua teoria [52 54], adotando, em 1836, a prescrição de polarização de Fresnel, de que as deformações da luz plano polarizada ocorrem perpendicularmente ao plano de polarização. Embora tal escolha resolvesse o problema da inversão das leis de Fresnel da reflexão, em meios isotrópicos, a dedução das mesmas continuava a depender de condições de contorno matemáticas introduzidas "ad hoc".

Nos domínios da dispersão da luz, Cauchy elaborou a ideia da dependência do raio de ação das forças elásticas interpartículas etéreas, com relação ao comprimento de onda da luz, propondo uma primeira teoria matemática da dispersão 52. Estabeleceu que

$$
v^{2}(\lambda)=v_{\infty}^{2}\left(1-\frac{4 \pi^{2} \Theta}{\lambda^{2}}\right),
$$

em que $v_{\infty}$ é a velocidade no meio para grandes comprimentos de onda $(\lambda)$ e $\Theta$ uma constante característica das suas propriedades dispersivas. Isso equivale dizer que o índice de refração $n$ pode ser escrito, até segunda ordem de $\lambda$ como

$$
n^{2}(\lambda)=A+\frac{B}{\lambda^{2}}
$$

Cauchy apresentou sua Mémoire sur la dispersion de la lumiére 55 em 1836, na qual elaborou em detalhe sua teoria da dispersão, a partir da estrutura de seu éter molecular, chegando a uma versão ampliada de $(34)$, envolvendo três parâmetros, na forma de um polinômio par de $1 / \lambda$ de ordem $1 / \lambda^{4}$.

A envergadura e a prioridade das contribuições de Cauchy, no desenvolvimento desse campo, são notórias e imortais. Mas Cauchy nunca hesitou em assumir hipóteses auxiliares "ad hoc", de inspiração puramente matemática, para alcançar os objetivos de compatibilizar suas postulações com os dados fenomenológicos. Nisso se afastou de uma formulação genuinamente mecânica dos fenômenos ópticos como resultado da elastodinâmica do éter luminífero [44, 56]. Essa foi nossa motivação principal para apontar o trabalho de Green como aquele que melhor encarna o "segundo ato", de nossa narrativa da teoria da birrefringência.

\section{Segundo Ato: Green}

A elastodinâmica da luz alcançou na obra de Green sua formulação madura, compatível com os preceitos gerais da mecânica em sua mais elevada forma, de uma formulação lagrangiana (para campos). É fato que tal teoria não foi capaz de reproduzir uma perfeita correspondência com a óptica de Fresnel, tanto na teoria da reflexão da luz polarizada, em meios isotrópicos [48], quanto na teoria da birrefringência 49]. Isso não deve ser visto como inconsistência interna dessa abordagem, mas como um sintoma, um indicativo, de que não é afinal uma teoria para aquilo que se propunha descrever: a elastodinâmica se revelaria incapaz de fundamentar a teoria ondulatória da luz. Como teremos oportunidade de ver adiante, o entendimento de tal incapacidade consumiu mais de 60 anos do pensamento científico, somente sendo abandonada com o próprio abandono da ideia de que há um éter luminífero.

Em "On the Laws of the reflexion and refraction of light at the common surface of two non-crystallized Media" 48 Green não negou a premissa de Cauchy de que a tensões no éter tivessem sua origem nas forças interpartículas constituintes do mesmo, mas optou por uma abordagem mais fenomenológica. Tratando o éter simplesmente como um continuum elástico, admitiu que o resultado médio final da soma de todas as interações não observáveis, para qualquer porção macroscópica do meio, fosse o de produzir o diferencial exato de uma função, introduzindo assim o potencial elástico, $\mathcal{U}$. O mesmo foi definido como função homogênea de grau dois das deformações, $\left\{e_{i j}\right\}$, e dependente de apenas dois parâmetros elásticos $(\mathcal{A}, \mathcal{B})$ no meio isotrópico, podendo ser escrito como

$$
\mathcal{U}_{i s o}=\left[\mathcal{B} \delta_{i k} \delta_{j l}+\frac{1}{2}(\mathcal{A}-2 \mathcal{B}) \delta_{i j} \delta_{k l}\right] e^{i j} e^{k l} .
$$

Já nesse trabalho deparou-se com a dificuldade de reconciliar seus resultados aos de Fresnel, particularmente na lei das tangentes para a reflexão da luz polarizada, devido à presença do modo acústico.

Sua formulação de uma teoria elastodinâmica da birrefringência surgiu em "On the Propagation of Light in Crystallized Media" [49. No setor puramente hookesiano do potencial elástico

$$
\mathcal{U}_{h}=\frac{1}{2} \mathcal{C}_{i j k l} e^{i j} e^{k l}
$$

introduziu não apenas dois, mas 21 coeficientes elásticos ${ }^{9}$ $\left\{\mathcal{C}_{i j k l}\right\}$, decorrentes das simetrias

$$
\mathcal{C}_{i j k l}=\mathcal{C}_{j i k l}=\mathcal{C}_{i j l k}=\mathcal{C}_{k l i j}
$$

${ }^{9}$ Hoje chamado tensor de elasticidade. 
Também considerou a possibilidade de que o éter não deformado fosse o sítio de tensões externas, $\left\{P_{i j}\right\}$, as quais podem estar presentes ou não.

O potencial elástico assim construído pode ser descrito como uma parte puramente hookesiana, $\mathcal{U}_{h}$, mais um termo de acoplamento com as tensões externas, da forma

$$
\mathcal{U}=\mathcal{U}_{h}+\frac{1}{2} P^{i j}\left(2 e_{i j}+\partial_{i} e_{k} \partial_{j} e^{k}\right) .
$$

Introduziu assim a densidade lagrangiana

$$
\mathcal{L}:=\mathcal{T}-\mathcal{U}=\frac{\rho}{2}\left|\frac{\partial \vec{e}}{\partial t}\right|^{2}-\mathcal{U},
$$

em que $\rho$ é a densidade do meio luminífero no interior do cristal, $\vec{e}$ o campo das deformações elásticas no meio. A dinâmica das deformações elásticas decorre então do princípio da mínima ação,

$$
\delta \mathcal{L}=0
$$

em um éter indefinidamente extenso, sem contribuições provenientes das fronteiras, no que resulta a equação de onda,

$$
\frac{\partial^{2} e^{i}}{\partial t^{2}}=\frac{1}{\rho}\left(\delta^{i j} P^{k l}+\mathcal{C}^{i k j l}\right) \partial_{k} \partial_{l} e_{j}
$$

Fresnel descreveu a birrefringência valendo-se de apenas 3 parâmetros, a saber, os elementos da matriz das elasticidades (9), eliminando "ad hoc" a possibilidade do éter propagar ondas longitudinais. No presente contexto, o meio anisotrópico genérico possui parâmetros livres em excesso para a formulação de uma teoria elastodinâmica da birrefringência. Assim Green impôs, inicialmente, simetrias por reflexão especular, dos planos coordenados e das deformações, restando 9 graus de liberdade independentes para os coeficientes $\left\{\mathcal{C}_{i j k l}\right\}$ isto é, nove constantes elásticas, as quais nomeou $(G, H, I ; P, Q, R ; L, M, N)$ :

$$
\begin{aligned}
\mathcal{C}_{1111}= & G, \quad \mathcal{C}_{2222}=H, \quad \mathcal{C}_{3333}=I, \\
& \mathcal{C}_{2233}=\mathcal{C}_{3322}=P, \\
& \mathcal{C}_{1133}=\mathcal{C}_{3311}=Q \\
& \mathcal{C}_{1122}=\mathcal{C}_{2211}=R \\
\mathcal{C}_{2323}= & \mathcal{C}_{3232}=\mathcal{C}_{2332}=\mathcal{C}_{3232}=L, \\
\mathcal{C}_{1313}= & \mathcal{C}_{3113}=\mathcal{C}_{1331}=\mathcal{C}_{3131}=M, \\
\mathcal{C}_{1212}= & \mathcal{C}_{2112}=\mathcal{C}_{1221}=\mathcal{C}_{2121}=N .
\end{aligned}
$$

Nesse sistema cartesiano também a matriz das tensões externas, $\left\{P_{i j}\right\}$, fica diagonalizada. Assim

$$
\left\{P^{i j}\right\} \equiv\left(\begin{array}{ccc}
A & 0 & 0 \\
0 & B & 0 \\
0 & 0 & C
\end{array}\right),
$$

como Green a designou.

\footnotetext{
${ }^{10}$ Hoje dito um meio anisotrópico ortorrômbico 57 .
}

Nisso reduziu sua teoria para algo similar à de Cauchy para a birrefringência, mas, diferentemente deste, como já dissemos, sua construção independe de considerações sobre as forças entre as hipotéticas partículas constituintes do éter, bastando considerar que o éter se configura para nós, fenomenologicamente, como um continuum elástico.

Mesmo assim, a teoria ainda apresenta parâmetros livres supérfluos, necessitando de vínculos adicionais. A restrição final de Green não teve por objetivo eliminar a onda longitudinal. Ao contrário, exigiu a sua existência como possível solução de (41), qualquer que fosse a direção de propagação $\hat{s}$. Isso assegura, por sua vez, a existência de dois modos transversos a este, e mutuamente ortogonais entre si, ao que Green chamou "princípio de Fresnel". Impondo então que onda plana longitudinal,

$$
\vec{e}_{L}(\vec{r}, t)=\alpha_{0} \mathrm{e}^{i k(\hat{s} \cdot \vec{r}-v t)} \hat{s}
$$

deve pertencer ao conjunto das soluções de (41), chega-se à

$$
\mathcal{C}_{i k j l} s^{k} s^{j} s^{l} \propto s_{i}
$$

como condição de consistência para que isto ocorra. Este vínculo equivale a novas restrições sobre (42), que são

$$
\begin{gathered}
G=H=I=\mu, \\
P=\mu-2 L, Q=\mu-2 M, R=\mu-2 N,
\end{gathered}
$$

restando assim quatro coeficientes elásticos $(L, M, N, \mu)$, conforme Green os nomeou.

Reunidas todas as restrições sobre o tensor de elasticidade torna-se possível explicitá-lo em partes irreduzíveis, na expressão anacrônica ${ }^{11}$

$$
\mathcal{C}_{i a j b}=\mu \delta_{i a} \delta_{j b}-\left(\epsilon_{i j r} \epsilon_{a b s}+\epsilon_{a j r} \epsilon_{i b s}\right) L^{r s} .
$$

sendo que $\left\{\epsilon_{i j k}\right\}$ é o símbolo de Levi-Civita, definido como usualmente,

$$
\begin{aligned}
& \epsilon_{123}=\epsilon_{231}=\epsilon_{312}=1 \\
& \epsilon_{132}=\epsilon_{213}=\epsilon_{321}=-1
\end{aligned}
$$

e zero em qualquer outra hipótese. Ainda, $\left\{L^{r s}\right\}$ é uma matriz simétrica, a qual é diagonal no mesmo sistema cartesiano que diagonaliza $\left\{P_{i j}\right\}$. Explicitamente

$$
\left\{L^{r s}\right\} \equiv\left(\begin{array}{ccc}
L & 0 & 0 \\
0 & M & 0 \\
0 & 0 & N
\end{array}\right) .
$$

Fixados assim todos os parâmetros que determinam a dinâmica das deformações no meio elástico anisotrópico

11 Fica evidente, aqui, que somente pelo uso de formalismo matemático indicial e anacrônico é que fomos capazes de condensar a teoria de Green em tão poucas linhas, sem perder os elementos essenciais. 
de Green, explicitaremos separadamente as equações das ondas acústica (longitudinal) e cisalhante (transversal). Para este fim vamos usar a decomposição de Hermann von Helmholtz (1821-1894), também de forma anacrônica, que não corresponde à análise de Green; embora em perfeita correspondência com a apresentada por ele. Introduzindo os campos auxiliares,

$$
\psi:=\nabla \cdot \vec{e}, \quad \vec{T}=\nabla \times \vec{e},
$$

estabelecemos as equações de onda para $\psi$ e $\vec{T}$.

Tomando-se, a divergência de 41) resulta que a equação da onda acústica é

$$
\frac{\partial^{2} \psi}{\partial t^{2}}=\frac{P^{j k}}{\rho} \partial_{j} \partial_{k} \psi+\frac{\mu}{\rho} \nabla^{2} \psi
$$

em que

$$
\nabla^{2}=\delta^{i j} \partial_{i} \partial_{j}
$$

é o Laplaciano. De modo similar, tomando-se o rotacional de (41), a equação da onda cisalhante é

$$
\frac{\partial^{2} T_{i}}{\partial t^{2}}=\frac{P^{j k}}{\rho} \partial_{j} \partial_{k} T_{i}-\frac{L^{j k}}{\rho}\left(\partial_{i} \partial_{k}-\delta_{i k} \nabla^{2}\right) T_{j},
$$

sendo a luz representada por essa última.

Temos agora todos os elementos necessários à discussão do problema de autovalor associado aos distúrbios propagados na elastodinâmica de Green. Tomamos soluções de onda plana para o modo longitudinal

$$
\psi(\vec{r}, t)=\psi_{0} \mathrm{e}^{i k(\hat{s} \cdot \vec{r}-u t)},
$$

em que $\psi_{0}$ é a amplitude constante.

Substituindo 48 em 46 encontramos a relação de dispersão para a onda acústica, a saber,

$$
u^{2}=\frac{\mu+P(\hat{s})}{\rho},
$$

na qual designamos por $P(\hat{s})$ a pressão externa normal à frente de onda, conforme 29, ficando assim determinada a velocidade, $u$, da onda acústica.

A onda plana associada ao modo transversal terá, por sua vez, polarização que designaremos por um versor $\hat{\eta}$, o qual é ortogonal à direção de propagação $\hat{s}$, como decorre de sua definição 45). Podemos então representá-la como

$$
\vec{T}(\vec{r}, t)=T_{0} \mathrm{e}^{i k(\hat{s} \cdot \vec{r}-v t)} \hat{\eta}, \quad \hat{s} \cdot \hat{\eta}=0,
$$

na qual $T_{0}$ é a amplitude constante. Substituindo (50) em 47) e reordenando convenientemente os termos da equação chega-se à

$$
O^{i j} \tilde{K}_{j k} \eta^{k}=v^{2} \eta^{i}
$$

na qual $O^{i j}$ é o mesmo definido em 16 ,

$$
\tilde{K}_{i j}=\frac{1}{\rho}\left(L_{i j}+P(\hat{s}) \delta_{i j}\right)
$$

e $P(\hat{s})$ o mesmo definido em (29). Fica assim determinada a velocidade $v$ das ondas cisalhantes, como os autovalores da equação acima.

A semelhança formal entre (51) e 15 é enganosa. $\mathrm{Na}$ formulação de Fresnel a matriz constante $\left\{K_{i j}\right\}$, dada em $(9)$, independe da direção normal à frente de onda. A própria essência da construção de Fresnel é de que os raios seguem caminhos no cristal que são selecionados unicamente pelo seu estado de polarização, mas independem da orientação da frente de onda. No contexto atual tal premissa é violada pela presença do termo $P(\hat{s})$ em $\left\{\tilde{K}_{i j}\right\}$, dada em (52). Conforme 29 a pressão externa será diferente para diferentes direções da normal $\hat{s}$.

O modo mais imediato de contornar essa dificuldade é assumir a inexistência de tensões externas

$$
P_{i j}=0,
$$

o que ficou conhecido como primeira teoria de Green da birrefringência. Nesta situação, conforme (49), (51) e 52 ,

$$
u^{2}=\frac{\mu}{\rho}
$$

$\mathrm{e}$

$$
O^{i j} \frac{L_{j k}}{\rho} \eta^{k}=v^{2} \eta^{i}
$$

De (15) e 55) se vê que os modos de polarização $\hat{p}$ de Fresnel são os mesmos modos de polarização $\hat{\eta}$ de Green, pela identificação

$$
K_{i j} \leftrightarrow \frac{L_{i j}}{\rho}, \quad \hat{p} \leftrightarrow \hat{\eta} .
$$

No entanto, se chamarmos $\hat{e}$ a correspondente polarização do vetor deformação original, $\vec{e}$, por 45 virá que

$$
\hat{\eta}=\hat{s} \times \hat{e} .
$$

Portanto, na primeira teoria de Green se está assumindo que as vibrações elásticas $\vec{e}$ ocorrem no próprio plano de polarização, diferentemente do que assumira Fresnel. Essa não equivalência é, no entanto, decorrente do fato de na teoria da elasticidade, como veio a ser formulada por Cauchy, Neumann, MacCullagh e Green, o que concorre para gerar pressão ou cisalhamento sobre a frente de onda, conforme 29) e (32), são as taxas de variação do vetor deformação, $\vec{e}$, e não seu valor absoluto.

Green indicou a possibilidade de reconciliar o seu esquema com a noção de polarização adotada por Fresnel, mantendo-se para isso as tensões externas. Mas o preço era alto: o critério de que a velocidade de propagação depende apenas do estado de polarização deve ser abandonado. Escolhendo convenientemente a relação entre os elementos de $\left\{P_{i j}\right\}$ e os de $\left\{L_{i j}\right\}$ mostrou 
ser possível preservar o referido critério apenas para propagações sobre os eixos principais do cristal. Esta ficou conhecida como segunda teoria de Green da óptica cristalina.

A construção de Green para tratar a birrefringência permite ilustrar duas características marcantes das teorias baseadas em um éter elástico: a presença do modo acústico e a ambiguidade em definir de forma unívoca a direção da vibração, paralela ou perpendicular ao plano de polarização. Ambas situações independem do fato do meio ser cristalino, apresentando-se mesmo no contexto de meios isotrópicos. Diversos autores tiveram atitudes distintas diante dessas questões. Green, por exemplo, havia assumido [48] que as ondas acústicas moviam-se infinitamente mais rápido que as cisalhantes, evitando assim que esse modo de propagação fosse efetivamente observável. Isso significa que considerou o éter infinitamente mais rígido à compressão/descompressão do que à distorção. Cauchy, por outro lado, investigou a possibilidade de tornar nula a velocidade do modo acústico [58, a partir dos anos de 1840. Isso pode ser alcançado assumindo que a resistência do éter a compressão/descompressão é negativa e de um valor convenientemente definido. Chamado de éter lábil por William Thomson ${ }^{12}$ (1824-1907), foi retomado em conexão com a teoria da reflexão [59] cinquenta anos mais tarde, à época da descoberta das "ondas elétricas". Também MacCullagh eliminou o modo longitudinal [46, 47] introduzindo um modo de elasticidade na qual as tensões no meio somente são produzidas em resposta à rotações locais, $\nabla \times \vec{e}$, indiferente à compressão/descompressão e distorção, postulando um potencial

$$
\mathcal{U}_{m a c}=\frac{1}{2} K_{i j}(\nabla \times \vec{e})^{i}(\nabla \times \vec{e})^{j},
$$

que corresponde, de acordo com (30) ou (32), a um meio não hookesiano.

Todas as situações elencadas acima correspondem à propriedades elásticas exóticas se pensamos nos sólidos elásticos convencionais.

\section{Terceiro Ato: Maxwell}

As descobertas de Michael Faraday (1791-1867) no campo da eletricidade e magnetismo [61, a partir dos anos de 1830, aprofundaram significativamente o entendimento da inter-relação destes dois domínios, a qual foi estabelecida por Hans Christian Oersted (17771851) com a descoberta da ação magnética da corrente elétrica, em 1820. Faraday estabeleceu também conexões importantes acerca da constituição elétrica e magnética da matéria, bem como a influência do magnetismo sobre

\footnotetext{
12 Segundo Thomson, foi Green quem primeiro introduziu o termo "potencial", em seu "Essay on the Application of Mathematical Analysis to the Theories of Electricity and Magnetism", de 1828 60.
}

a luz polarizada. Especulou de modo qualitativo sobre a possibilidade de unificação dos domínios da eletricidade, do magnetismo e das radiações, a partir de sua concepção de linhas de força. A visão de Faraday inspirou os teóricos a traduzirem tal possibilidade de unificação em um conjunto formal de equações que a encarnasse. Tal tarefa foi iniciada por Thomson [62 67], mas tomou forma mais definitiva na obra de James Clerk Maxwell (1831-1879).

A primeira formulação das equações eletromagnéticas, por Maxwell, incluindo o termo da corrente de deslocamento, se deu em "On Physical Lines of Force" 68. Nessa ocasião o campo eletromagnético não foi concebido como possuidor de uma realidade independente, mas resultado de movimentos e tensões de um éter molecular constituído de "vórtices" elásticos. Nesse meio, o campo magnético $\vec{H}$ é medida do movimento turbilhonar, a permeabilidade magnética, $\mu$, é medida de sua densidade, o vetor deslocamento $\vec{D}$ é medida da deformação elástica média tomada sobre o vórtice, e a constante dielétrica $\varepsilon$ fornece medida do inverso da constante de rigidez elástica do meio. Demonstrou então que as ondas transversais nele propagadas possuem velocidade

$$
v=\sqrt{\frac{1}{\mu \varepsilon}} .
$$

No sistema de padrões então adotados, os valores de referência eram aqueles do ar, onde $\mu_{0}=1$ e $\varepsilon_{0}$ coincidia com o fator de conversão entre os antigos padrões eletrostático e eletrodinâmico de carga elétrica. Tal fator havia sido medido por Wilhelm Weber (18041891) e Rudolf Kohlrausch (1809-1858) 69] e possuía um valor suficientemente próximo ao da velocidade da luz no ar. Maxwell reivindicou realizada uma possível "unificação" entre eletricidade, magnetismo e óptica, conforme especulada por Faraday. De (58) estabeleceu a relação necessária entre a permissividade $(\varepsilon)$, a permeabilidade $(\mu)$ e o índice de refração $(n)$, como

$$
\frac{\varepsilon}{\varepsilon_{0}}=\frac{n^{2}}{\mu}
$$

A obtenção de medidas de precisão de $\varepsilon$ para compará-lo ao índice de refração de meios transparentes tornou-se um dos seus objetivos, para consolidação experimental de sua teoria [70].

Três anos depois, em "A Dynamical theory of the electromagnetic field" [71] Maxwell abandonou o "mar de vórtices" étereos, mas manteve as relações matemáticas que lhe pareciam convenientes ao programa de unificação, suprimindo porém a menção ao mecanismo que conectava as variáveis de campo às propriedades mecânicas do éter. Foi neste trabalho que Maxwell abordou a birrefringência, pela primeira vez, em conexão com sua teoria eletromagnética da luz.

Em "Dynamical Theory" não encontramos as equações de Maxwell na forma padrão dos dias atuais, como 
equações para as divergências e os rotacionais dos campos $(\vec{E}, \vec{B})$. Ao contrário, a presença dos potenciais eletromagnéticos $(\psi, \vec{A})$ foi enfatizada, de forma explícita nas equações de campo, pois Maxwell via o potencial vetor $\vec{A}$ como um dos elementos fundamentais de sua teoria 13 O campo elétrico, por exemplo, foi frequentemente tratado como variável de campo secundária, decorrendo dos potenciais na forma usual

$$
\vec{E}=-\frac{\partial \vec{A}}{\partial t}-\nabla \psi
$$

A permeabilidade magnética $(\mu)$ e a permissividade dielétrica $(\varepsilon)$ foram por ele introduzidas agora nas equações

$$
\vec{E}=\frac{1}{\varepsilon} \vec{D} \quad \mu \vec{H}=\nabla \times \vec{A}
$$

às quais chamou de "equação da elasticidade elétrica" $\mathrm{e}$ "equação da força magnética".

Na seção "Teoria eletromagnética da luz" [71, p. 577], demonstrou a presença de "ondas eletromagnéticas", no meio dielétrico, valendo-se de 61) e da "equação das correntes"

$$
\nabla \times \vec{H}=\frac{\partial \vec{D}}{\partial t}
$$

no que resultou

$$
\mu \varepsilon \frac{\partial^{2} \vec{A}}{\partial t^{2}}-\nabla^{2} \vec{A}=\nabla\left(\nabla \cdot \vec{A}+\mu \varepsilon \frac{\partial \psi}{\partial t}\right),
$$

da qual, tomando-se o rotacional produz a equação de onda para o campo magnético $\vec{H}$,

$$
\mu \varepsilon \frac{\partial^{2} \vec{H}}{\partial t^{2}}-\nabla^{2} \vec{H}=0
$$

Formalmente nenhum problema, mas o leitor até o momento não saberia dizer se a "onda eletromagnética" é uma onda de $\vec{A}$ ou uma onda de $\vec{H}$. Maxwell pareceu sugerir a segunda opção, o que levou à mesma previsão (58) para a velocidade de propagação os "distúrbios eletromagnéticos". Da mesma forma para o índice de refração estabeleceu novamente (59) como a "relação entre o indice de refração e o caráter eletromagnético da substância".

A birrefringência surgiu na seção "Propagação de distúrbios eletromagnéticos em meios cristalinos", onde considerou a possibilidade do meio apresentar anisotropia tanto dielétrica como magnética. Introduziu então $\left\{\kappa_{i j}\right\}$ e $\left\{\mu_{i j}\right\}$ tais que 61 torna-se agora

$$
E_{i}=\kappa_{i j} D^{j} \quad \mu_{i j} H^{j}=(\nabla \times \vec{A})_{i} .
$$

13 Um ponto problemático na medida em que a invariância de calibre das equações eletromagnéticas não havia sido então estabelecida e, portanto, o caráter matemático e acessório dos potenciais.
A partir de 60, 62 e 65 construiu novamente a equação de onda para $\vec{A}$, daí resultando

$\left(\kappa^{-1}\right)^{i j}\left(\frac{\partial^{2} A_{j}}{\partial t^{2}}+\partial_{j} \frac{\partial \psi}{\partial t}\right)+\left(\mu^{-1}\right)_{k p} \epsilon^{i j k} \epsilon^{p q r} \partial_{j} \partial_{q} A_{r}=0$,

em que $\left(\kappa^{-1}\right)^{i j}$ indica o elemento $(i j)$ da matriz inversa da matriz cujos elementos são $\kappa_{i j}$. Analogamente para $\left(\mu^{-1}\right)_{i j}$.

A presença do potencial $\psi$ na equação torna possível um modo longitudinal de $\vec{A}$, o qual Maxwell descartou, juntamente com o próprio potencial escalar $\psi$. Alegou que "as equações não indicam que tal distúrbio, se possível, possa ser propagado, na medida em que não temos nenhuma outra relação entre" $\psi$ e $\vec{A} \cdot 14$

Resulta então uma equação de onda para $\vec{A}$, a qual Maxwell considerou em duas situações: No caso de anisotropia puramente dielétrica,

$$
\mu_{i j}=\mu \delta_{i j}
$$

a equação 66 reduz-se à

$$
\left(\kappa^{-1}\right)_{i j} \frac{\partial^{2} A^{j}}{\partial t^{2}}+\frac{1}{\mu}\left(\partial_{i} \partial_{j}-\delta_{i j} \nabla^{2}\right) A^{j}=0 .
$$

Podemos inferir que o equivalente da equação anterior para o vetor deslocamento elétrico, $\vec{D}$, é

$$
\frac{\partial^{2} D_{i}}{\partial t^{2}}+\frac{\kappa^{j k}}{\mu}\left(\partial_{i} \partial_{j}-\delta_{i j} \nabla^{2}\right) D_{k}=0 .
$$

embora Maxwell não a explicite. A mesma pode ser convertida em equação algébrica, supondo-se uma solução de onda plana para $\vec{D}$

$$
\vec{D}(\vec{r}, t)=D_{0} \mathrm{e}^{i k(\hat{s} \cdot \vec{r}-v t)} \hat{\xi},
$$

em que $\hat{\xi}$ identifica o estado de polarização do deslocamento elétrico. A relação de dispersão que daí decorre é

$$
O^{i j}\left(\frac{\kappa_{j k}}{\mu}\right) \xi^{k}=v^{2} \xi^{i} .
$$

De 15 e 70 se vê que os modos de polarização $\hat{p}$ de Fresnel são os mesmos modos de polarização $\hat{\xi}$ do vetor deslocamento elétrico, pela associação

$$
K_{i j} \leftrightarrow \frac{\kappa_{i j}}{\mu}, \quad \hat{p} \leftrightarrow \hat{\xi},
$$

o que levou Maxwell a ressaltar que este é o caso em que o vetor deslocamento elétrico $\vec{D}$ oscila perpendicularmente ao plano de polarização.

\footnotetext{
14 Tal afirmação é incorreta, pois sabemos que há uma infinita variedade de relações possíveis entre $\psi$ e $\vec{A}$. Por exemplo, a condição de calibre de Lorentz. A solução descartada corresponde a tomarmos $\vec{A}$ como campo de puro calibre, ao qual não se associa física alguma, no contexto clássico. Vê-se aqui, portanto, uma dificuldade que somente se coloca em decorrência da condição ainda incipiente da teoria eletromagnética nos primeiros trabalhos de Maxwell.
} 
No caso em que a anisotropia é puramente magnética

$$
\kappa_{i j}=\frac{1}{\varepsilon} \delta_{i j}
$$

considerações similares sobre (66) levam à equação de onda

$$
\frac{\partial^{2} A^{i}}{\partial t^{2}}+\frac{\left(\mu^{-1}\right)_{k p}}{\varepsilon} \epsilon^{i j k} \epsilon^{p q r} \partial_{j} \partial_{q} A_{r}=0,
$$

ou o equivalente, para o vetor deslocamento

$$
\frac{\partial^{2} D^{i}}{\partial t^{2}}+\frac{\left(\mu^{-1}\right)_{k p}}{\varepsilon} \epsilon^{i j k} \epsilon^{p q r} \partial_{j} \partial_{q} D_{r}=0
$$

Convertida em equação algébrica, por $(69)$, resulta

$$
O^{i j}\left[\frac{\left(\mu^{-1}\right)_{j k}}{\varepsilon}\right](\hat{s} \times \hat{\xi})^{k}=v^{2}(\hat{s} \times \hat{\xi})^{i},
$$

o que equivale, na correspondência com 15 , à

$$
K_{i j} \leftrightarrow \frac{\left(\mu^{-1}\right)_{i j}}{\varepsilon}, \quad \hat{p} \leftrightarrow \hat{s} \times \hat{\xi},
$$

o que levou Maxwell à conclusão de que o vetor deslocamento oscila no plano de polarização, em tais circunstâncias. A anisotropia magnética é, portanto, o análogo da anisotropia de elasticidade, na elastodinâmica da primeira teoria de Green. A anisotropia dielétrica não tem análogo naquele contexto, pois lá não há uma anisotropia inercial $\left(\rho \rightarrow \rho_{i j}\right)$.

A anisotropia magnética era fato mais bem estabelecido quando Maxwell escreveu essas linhas, tendo sido William Thomson quem primeiramente escreveu a equação constitutiva 65

$$
B_{i}=\mu_{i j} H^{j},
$$

na formulação matemática das características do bismuto cristalino, ao qual Faraday atribuiu eixos "magnetocristalinos" [72, à época em que Faraday descobriu também o diamagnetismo. Maxwell citou os trabalhos de Faraday e de Plucker 73, acerca da anisotropia magnética, porém manifestou-se cético de que este fosse o fator responsável pela birrefringência, dada a intensidade dos campos magnéticos envolvidos para manifestála. Com relação a anisotropia dielétrica citou resultados de Knoblauch 74 que indicavam a possibilidade de tal anisotropia. Terminou de forma cautelosa afirmando que

"Mais experimentos sobre as propriedades magnéticas e dielétricas dos cristais são necessárias antes que possamos decidir se a relação destes corpos com as forças elétricas e magnéticas são as mesmas, quando estas forças são permanentes e quando são alternadas com a rapidez das vibrações da luz." [71, p. 586]
Quase uma década mais tarde, em 1873, surgiu a primeira edição do "A treatise on electricity and Magnetism" 75]. Nele Maxwell reuniu, em dois volumes, a melhor síntese que pôde fazer de suas pesquisas eletromagnéticas. Daqui em diante considerou que a propriedade relevante na birrefringência usual é a permissividade dielétrica $(\varepsilon)$ dos cristais. No parágrafo 788 Maxwell afirmou:

\section{"Não existem meios transparentes para os quais a capacidade magnética difere daquela do ar mais do que uma fração muito pequena. Assim a parte principal da diferença entre estes meios deve depender da sua capacidade dielétrica." [75, p. 388]}

Advertiu, entretanto, que a relação da permissividade dielétrica $(\varepsilon)$ com o índice de refração $(n)$ que emerge de suas equações,

$$
\varepsilon=n^{2}
$$

deve ser entendida como modelo, tomando-se o índice de refração correspondente à ondas de longos períodos $\left(n_{\infty}\right)$ "porque estas são as únicas ondas cujos movimentos podem ser comparados com os processos lentos pelos quais determinamos a capacidade de um dielétrico." No parágrafo 789, nos informou que a única permissividade então conhecida, com a precisão requerida, era a da parafina sólida, conforme medidas por Gibson e Barclay [76]. Para efeito de comparação com o índice de refração tomou dados de Gladstone obtidos para a parafina derretida "para comprimentos de onda infinitos". Eram eles

$$
\varepsilon=1,9754 \rightarrow \sqrt{\varepsilon}=1,405, \quad n_{\infty}=1,422 .
$$

Maxwell comenta:
"A diferença entre estes números é maior do que aquilo que se pode atribuir a erros de observação, e mostra que nossa teoria sobre a estrutura dos corpos deve ser muito aper- feiçoada antes que possamos deduzir suas propriedades ópticas de suas propriedades elétricas. [75, p. 389]

Medidas subsequentes para a parafina ratificaram que $\varepsilon \approx n_{\infty}^{2}$

O comentário de Maxwell, acima, talvez se associe à descoberta da dispersão anômala, por Leroux [77. em 1862: ao passar raios de diferentes cores através de um prisma preenchido com vapor de iodo, Leroux observou uma inversão no ordenamento das cores, sendo o vermelho defletido mais intensamente que o azul, ao que chamou de dispersão anômala. Isso levou Maxwell a tratar do problema da dispersão em 1869 (conforme nota de Lorde Rayleigh [78, publicada vinte anos após a morte de Maxwell). Imaginando um meio elástico em que coexistem nele imersos "átomos de outra matéria" e 
fazendo conjecturas sobre as forças entre uma porção do meio e os átomos nele existentes, deduziu uma equação de dispersão da forma

$$
n^{2}=1+\frac{\sigma}{\rho} \frac{\omega_{0}^{2}}{\omega_{0}^{2}-\omega^{2}},
$$

em que $\omega$ é a frequência da onda que atravessa o meio, $\omega_{0}$ a frequência natural de oscilações dos átomos nele imersos, e $(\rho, \sigma)$ parâmetros do meio e dos átomos, respectivamente. Tal fórmula servia de modelo mecânico para a dispersão normal, a qual podia ser caracterizada como aquela que ocorre quando a onda através do meio possui frequência $\omega$ inferior à $\omega_{0}$, isto é, grandes comprimentos de onda. Em tais circunstâncias a expansão em potências de $\left(\omega / \omega_{0}\right)^{2}$ fornece em primeira aproximação

$$
n^{2} \approx\left(1+\frac{\sigma}{\rho}\right)+\left(\frac{\sigma}{\rho \omega_{0}^{2}}\right) \omega^{2},
$$

o que é compatível com a equação de Cauchy (35). Se, no entanto, a onda possuir frequência próxima à $\omega_{0}$ poderá surgir um pico de refração daquele modo, no que constituiria a dispersão anômala. Assim, a validade da equação de Cauchy na dispersão da luz visível estaria indicando que $\omega_{0}$ estaria além do violeta nas substâncias consideradas. Maxwell jamais elaborou seu modelo sob a forma de uma teoria da estrutura da matéria, mas o que foi dito fornece elemento adicional para indicarmos que ele não via a discrepância entre $\varepsilon$ e $n^{2}$ como um embaraço para sua teoria eletromagnética da luz, e sim como uma dificuldade ligada à ignorância acerca da estrutura da matéria bruta, onde ocorre não somente dispersão e também absorção.

Na seção "Propagação de ondas planas em um meio cristalino", parágrafos 794-797, tratou a birrefringência a partir das equações constitutivas

$$
D_{i}=\varepsilon_{i j} E^{j} \quad \nabla \times \vec{A}=\mu \vec{H},
$$

e sendo $\vec{E}$ dado conforme 60 .

A equação "de propagação do distúrbio eletromagnético" é apresentada - novamente - em termos dos potenciais,

$$
\mu \varepsilon_{i j}\left(\frac{\partial^{2} A^{j}}{\partial t^{2}}+\partial_{j} \frac{\partial \psi}{\partial t}\right)+\left(\partial_{i} \partial_{j}-\delta_{i j} \nabla^{2}\right) A^{j}=0
$$

com a presença do potencial escalar $\psi$, como ocorrera antes no "Dynamical Theory", equação (66), o que implica na possibilidade da onda longitudinal para $\vec{A}$, proporcional à $\psi$. Agora, porém, diferentemente do que fizera no "Dynamical theory", procura oferecer a motivação física para descartá-la. Tal solução seria

"normal a frente de onda e proporcional à densidade elétrica volumétrica. Como o meio é um não condutor, a densidade elétrica em um dado ponto qualquer é constante e, portanto, o distúrbio [longitudinal] indicado por essas equações não é periódico e não pode constituir uma onda. Devemos portanto considerar $\psi^{\prime \prime}=0$ nas investigações da onda." [75, p. 393]

Eliminado $\psi$ segue então, em conformidade com o que foi estabelecido nas considerações sobre o "Dynamical Theory", que a equação de autovalor para o deslocamento elétrico é 70), em correspondência direta com a equação das normais de Fresnel (15), apenas que a constante dielétrica foi agora nomeada como

$$
\varepsilon_{i j}=\left(\kappa^{-1}\right)_{i j} .
$$

Maxwell também destacou, em decorrência de

$$
\vec{D} \cdot \hat{s}=0
$$

que a direção de polarização $\hat{\xi}$ do vetor deslocamento é determinada, também em conformidade com (13), pela equação

$$
\left(\varepsilon^{-1}\right)_{i j} \xi^{i}(\hat{s} \times \hat{\xi})^{j}=0 .
$$

Concluiu suas considerações sobre a birrefringência chamando atenção ao fato de que na teoria eletromagnética da luz não há o problema da onda longitudinal[15 o qual "constitui um dos principais problemas da teoria ordinária", apontando a crítica [79] de George Gabriel Stokes (1819-1903). Maxwell não mais reformulou o que estabeleceu até aqui sobre a birrefringência.

Neste meio tempo, na Alemanha, Helmholtz trouxe o eletromagnetismo ao centro de seus interesses [80, 83], considerando que esse campo de investigação era uma "mata sem veredas". A eletrodinâmica weberiana - da ação à distância - constituía a abordagem predominante dos físicos continentais e as críticas de Helmholtz, tanto às ideias de Maxwell quanto às de Weber, contribuíram para a gradual disseminação da teoria do campo eletromagnético - da ação contígua - entre os continentais. Vale lembrar que foi por iniciativa de Helmholtz que a Academia de Ciências da Prússia ofereceu, em 1879, o prêmio para quem demonstrasse que variações "de polarização" (correntes de deslocamento) produziam os mesmos efeitos eletrodinâmicos que corrente de condução. Estimulou seu jovem pupilo Heinrich Hertz (1857-1894) à concorrê-lo, o que foi afinal a motivação que levou Hertz a demonstrar o efeito em 1886 [84, p. 95-106] e,

\footnotetext{
15 Ao manifestar-se dessa maneira, Maxwell está claramente se referindo à onda de deslocamento elétrico. Porém, ele reiteradamente usa o termo "distúrbio eletromagnético " para referir-se às variações do potencial $\vec{A}$, sendo a equação de onda predominantemente deduzida e exibida nesta variável. Manifesta-se aqui, mais uma vez, a ambivalência de Maxwell em dizer ao seu leitor quem é afinal a "onda eletromagnética". Tal ambivalência somente pode ser superada se promovemos $(\vec{E}, \vec{B})$ à condição de campos físicos primários e rebaixamos os potenciais $(\psi, \vec{A})$ à condição de variáveis auxiliares, o que Maxwell relutava em fazer. Ou o fazia conforme a conveniência.
} 
superando os limites do prêmio da academia, a produzir as "ondas elétricas" no ar [84, p. 124-136].

Naquele ano de 1873, o jovem Ludwig Boltzmann (1844-1906) trabalhava no laboratório de Helmholtz, onde realizou medidas da constante dielétrica $(\varepsilon)$ de vários corpos transparentes comparando-a com os correspondentes índices de refração $(n)$ das mesmas, encontrando boa concordância da relação $\varepsilon=n^{2}$. Helmholtz, porém, havia descuidadamente informado Boltzmann que a dependência era de simples proporcionalidade $\varepsilon \propto$ $n$, segundo Maxwell, o que Boltzmann claramente sabia que podia refutar, a partir de seus dados experimentais. Nas palavras de Boltzmann

\section{" [...] pensei ter refutado completamente Maxwell, com os firmes resultados de Berlim e já com a noção de publicá-los quando me veio a súbita ideia de olhar a fórmula de Maxwell, uma vez mais, e encontrando $n=$ $\sqrt{\varepsilon}$, a qual funcionava bem". [85, p. 213]}

Boltzmann afinal publicou não somente seus resultados para os gases [86, 87] como também o caso de anisotropia dielétrica no enxofre cristalino 88 .

\section{A consolidação da teoria eletromagnética da luz}

No presente, a teoria da birrefringência está incorporada à teoria eletromagnética 29, 89. Como se chegou a isso é a história cujos contornos queremos delinear.

Maxwell faleceu em 1879, enquanto preparava a $2^{\mathrm{a}}$ edição do "Treatise". Tal edição surgiu em 1881 90] organizada por William Davidson Niven (1842-1917), que manteve o texto revisado de Maxwell e acrescentou notas explicativas onde julgou pertinente. No parágrafo 789 Niven acrescentou uma nota sobre o trabalho de Hopkinson [91, 92] que determinou a permissividade de vários vidros, encontrando $\varepsilon>n^{2}$. Medidas tomadas sobre óleos 93 , encontrou boa concordância $\left(\varepsilon=n_{\infty}^{2}\right)$ em hidrocarbonetos e grande discrepância $\left(\varepsilon>n_{\infty}^{2}\right)$ em óleos animal e vegetal. Nada foi acrescido à seção, "Propagação de ondas planas em um meio cristalino", parágrafos 794-797. A segunda edição marca também a difusão do "Treatise" no continente. Em 1883 surgiu a $1^{\text {a }}$ edição alemã do "Treatise", por Max Bernhard Weinstein [85, p. 214]. Em 1885 a $1^{\text {a }}$ tradução francesa do volume 1, a partir da $2^{\mathrm{a}}$ edição inglesa, por G. Séligmann-Lui 94] e somente em 1887 o volume 2, também por G. Séligmann-Lui [95].

$\mathrm{Na}$ década de 1880 a teoria eletromagnética da luz tornou-se uma obra coletiva. Os artigos que Oliver Heaviside (1850-1925) iniciou em 1885 no "The Electrician" [96, 97], promoveram a depuração das ideias originais de Maxwell, nos legando as equações "duplex", as que hoje são chamadas "Equações de Maxwell", juntamente com o formalismo operatorial-vetorial. Hertz, em seus artigos teóricos [84, p. 195-268] 98, também contribuiu para tal depuração. O resultado mais visível disso foi a eliminação dos potenciais do corpo das equações fundamentais da teoria eletromagnética [99, p. 155-180]. Na segunda metade da década temos a produção de ondas eletromagnéticas em laboratório, por Hertz [84, p. 29-53]. Retrospectivamente tal descoberta é o ponto de inflexão na história da teoria eletromagnética, mas as ondas hertzianas não foram vistas de imediato como "prova" da veracidade da teoria eletromagnética da luz de Maxwell. O próprio Hertz pontuou que observara ondas de força eletromotriz, mas não a parceira magnética que devia lhe acompanhar. Também encontrou velocidades distintas das "ondas hertzianas" no ar e no condutor, diferentemente das expectativas teóricas [84, p. 1-28]. A óptica das "ondas hertzianas", por outro lado, possibilitava o estudo das propriedades eletromagnéticas e ópticas da matéria fora do espectro visível, do infravermelho e do ultravioleta, as radiações então conhecidas. A possibilidade da teoria eletromagnética da luz vir a ser a moldura disso tudo lhe dava, como disse Hertz, um "apelo superior".

Na década de 1890 vemos os livros universitários começarem a refletir a necessidade de se posicionar diante da teoria eletromagnética da luz, abordando os acordos e desacordos das constantes ópticas e eletromagnéticas, e sua conexão com a unificação maxwelliana.

Em 1890 Henri Poincaré (1854-1912) publicou "Électricité et optique - Les théories de Maxwell" [100]. Apresentou a dedução-padrão da relação $\varepsilon=n^{2}$ via equações de Maxwell, indicando-nos sua validade para ondas de "longo período", conforme indicado por Cauchy (35). Também apontou as limitações disso, ao advertir que experiências no espectro infravermelho ("calorifique") indicavam a necessidade de substituir a fórmula de Cauchy por

$$
n=A \lambda^{2}+B+\frac{C}{\lambda^{2}},
$$

o que considerou a causa principal das discrepâncias. Reiterou que à época em que Maxwell escreveu o "Treatise" o único dielétrico de permissividade conhecida com precisão era a parafina, citando Gibson e Barclay [76]. Considerou medidas subsequentes, citando resultados conflitantes de Hopkison [92] em vidros e em óleos vegetais e animais. Chamou atenção para a discordância na água, onde Gouy [101] encontrou $\varepsilon=80$, ou $\sqrt{\varepsilon} \approx 9$, o que implicaria num índice de refração $n$ sete vezes maior que o real. Apontou também a concordância nos hidrocarbonetos líquidos, citando Hopkinson [93], Négréano e Palaz, e nos gases fornecendo os dados de Boltzmann [86, 87]. Nos meios anisotrópicos, apresentou a dedução-padrão da relação $\varepsilon_{i}=n_{i}^{2}$ via equações de Maxwell. Resultados de Jacques Curie (1855-1941) para a permissividade do quartzo, espato, turmalina, berilo, etc. [102], conforme indicou, apontavam invariavelmente que $\varepsilon_{i}>n_{i}^{2}$, embora houvesse conformidade com o fato de que a maior/menor permissividade ocorre na direção do maior/menor índice de refração. Indicou a igualdade 
bem estabelecida "para o enxofre cristalizado", citando Boltzmann [88. Sentenciou afinal que a relação $\varepsilon_{i}=$ $n_{i}^{2}$ era verificada de modo muito imperfeito. Além da dispersão, apontou a condutibilidade (absorção) das substâncias, como possível fonte de discrepâncias. Em 1891 Poincaré afirmou, sobre a teoria eletromagnética da luz, que

\section{"A teoria está incompleta, as experiências são pouco numerosas e contraditórias. É por- tanto impossivel decidir se há concordância ou discordância." [103, p. 258]}

Em 1892 surgiu a $3^{\text {a }}$ edição do "Treatise" [104 organizada por Joseph John Thomson (1856-1940). No parágrafo 789 , acresceu dados de permissividade dielétrica do vidro medidas em condições de oscilações elétricas da ordem de 25 milhões de ciclos por segundo, nas quais se aproximam $\varepsilon$ e $n^{2}$, citando resultados próprios [105] e de Blondot [106]. Porém, também mencionou que Lecher [107] obteve resultados opostos. Sobre a birrefringência nada acrescentou aos parágrafos 794-797. J.J. Thomson também publicou, em 1893 um livro-suplemento "pretendido como uma sequência ao Tratado de Electricidade e Magnetismo do professor Clerk-Maxwell" 108, no qual forneceu um quadro geral das medidas de $\varepsilon$ e $n$, estabelecidas por técnicas de campos que variam lentamente bem como por oscilações rápidas. No primeiro caso apresentou as já mencionadas medidas de Hopkinson, Boltzmann, Négréano, Curie e outros [108, p. 468-470]. O quadro que daí emerge indica que $\varepsilon \approx n^{2}$ funciona bem para hidrocarbonetos, gases permanentes e parafina, enquanto que para as outras substâncias $\varepsilon>n^{2}$. Nos meios cristalinos $\varepsilon_{i}>n_{i}^{2}$ parece ser a regra, da qual o cristal de enxofre é a notável exceção. J.J. Thomson relativizou o significado das discrepâncias, lembrando que nas equações de Maxwell não há qualquer termo que permita descrever a dispersão, sendo portanto alheia à teoria eletromagnética da luz em si. Do lado da matéria, mesmo o valor $n_{\infty}$ pode ser pouco significativo, pois é inferido da fórmula de Cauchy (35) a qual é invalidada se houver dispersão anômala 80 , como indicara Poincaré. Avaliou que a dificuldade seria superada se medidas de $\varepsilon$ fossem feitas a partir de ondas eletromagnéticas do mesmo comprimento de onda que as ondas luminosas usadas na determinação de $n$, o que era impraticável em laboratório. As "ondas de hertzianas", muito mais longas que a luz visível, eram, no entanto, as mais curtas que podiam ser produzidas em laboratório. Discutiu então resultados obtidos por técnicas de oscilações rápidas, os seus próprios 109, bem como os de Rubens \& Arons [110, 111] e Blondot [106, os quais produziam resultados tanto consonantes quanto discordantes, em relação às medidas com campos que variam lentamente.

Em 1894 surgiu o livro de Heaviside " Electromagnetic Theory "112. Maxwelliano de primeira hora, na seção "Efeitos da Eolotropia. Superfícies de onda Ópticas. Eletromagnética versus teorias Sólido-elásticas", avaliou que teoria eletromagnética da luz era superior às teorias elásticas, particularmente na descrição da dupla refração, que pode ter origem dielétrica, magnética ou ambas. A permissividade e a permeabilidade são, afirmou, grandezas mensuráveis diretamente em laboratório, enquanto que nas teorias elásticas as correspondentes grandezas são características elástica e inercial do éter, às quais são inacessíveis à mensuração direta. Defendeu assim a inexorável prevalência da teoria eletromagnética da luz sobre as teorias elastodinâmicas.

Tornava-se, assim, consensual que o problema das concordância/discordância das constantes eletromagnéticas e ópticas estava menos ligado à teoria eletromagnética da luz e mais ligado à ignorância acerca na estrutura íntima da matéria. Foi nesse momento, pois, que entrou no debate o elemento final desta trama: o elétron.

Surgido das especulações teóricas de Hendrik Antoon Lorentz (1853-1828), em 1892, o elétron resultou do esforço em reconciliar a teoria de campo de FaradayMaxwell-Heaviside com uma visão atomística de eletricidade, herdada da tradição continental, particularmente de Helmholtz, mas que remontava à eletrodinâmica de Weber. Tais partículas eram dotadas de carga elétrica e pensadas como constituintes da matéria ordinária. Permaneciam presas elasticamente no interior das moléculas materiais e intermediavam a interação entre a matéria bruta e o éter estacionário. Em "La théorie eletromagnétique de Maxwell et son apllication aux courps mouvants" [113] surgiu, então, a lei de força que hoje leva seu nome, da ação do "éter sobre a partícula vibrante" de carga $e$,

$$
\vec{f}=e \vec{E}+e \vec{v} \times \vec{B} .
$$

A distinção entre o elétron $(e)$ e o éter $(\vec{E}, \vec{B})$ os quais podem, no entanto, atuar um sobre o outro, permitiu a Lorentz obter a primeira versão de sua equação da dispersão, calculada a partir da modificação induzida no meio, pelos elétrons que nele chacoalham, devido à ação dos campos da onda eletromagnética. Ao fazê-lo tornamse parte ativa da dinâmica da própria onda, no interior da matéria. Disso resultou [113, p. 134], o que podemos escrever, de forma anacrônica,

$$
n^{2}=1+\frac{N e^{2} / m \varepsilon_{0}}{\left(\omega_{0}^{2}-\omega^{2}\right)}
$$

em padrões do sistema internacional. Nessa expressão $N$ é o número de elétrons por unidade de volume, $e$ a sua carga, $m$ sua massa, $\omega_{0}$ sua frequência natural e $\omega$ a frequência da onda eletromagnética que atravessa o meio dielétrico, sem absorção, e $\varepsilon_{0}$ a permissividade do vácuo. Elaborando melhor sua visão no "Versuch einer Theorie der electrischen und optischen Erscheinungen in bewegten Körpern" 114, de 1895, Lorentz colocou a teoria do elétron no centro da arena em que as fronteiras da teoria eletromagnética, da óptica e da estrutura da matéria se tocavam. Na verdade pode-se dizer que a década de 90 viu nascer três "teorias do elétron", 
independentemente, por Lorentz, Joseph Larmor (18571942) e Emil Wiechert (1861-1928) [99, p. 285-321]. Mencionamos a de Lorentz por ser aquela que mais diretamente impactou a teoria da dispersão e absorção.

Em 1896, Peter Zeeman (1865-1843) descobriu o efeito que hoje leva seu nome, da separação das linhas espectrais das linhas-D do Sódio, induzidas pelo campo magnético. Lorentz forneceu a explicação teórica e quantitativa do fenômeno a partir da "teoria do elétron", previu os estados de polarização das linhas espectrais e suas frequências conforme observadas no efeito Zeeman normal. Os dados de Zeeman e a formulação teórica de Lorentz, possibilitaram determinação da razão carga/massa do elétron em $e / m=10^{7} e . m . u$. No ano seguinte, resultados de J.J.Thomson para a razão $e / m$ obtidos da deflexão de raios catódicos revelaram estreito acordo com os valores de Zeeman 115. J.J.Thomson mostrou ainda que tais "corpúsculos", constituintes dos raios catódicos, eram os mesmos presentes no efeito termiônico e no efeito fotoelétrico [116], abrindo caminho para o entendimento de que ali estava o primeiro constituinte elementar da matéria, descoberto pelo homem.

Em 1900, por fim, surgiu o livro de Paul Drude (1863-1906) "Lehrbuch der Optik" [117]. Nele a teoria eletromagnética é apontada como fundamentação mais adequada para a descrição da óptica, pois "permite o tratamento mais simples e consistente das relações $d a$ óptica". Deduziu que $n^{2}=\varepsilon$ e $n_{i}^{2}=\varepsilon_{i}$ para meios isotrópicos e anisotrópicos, respectivamente, via equações de Maxwell, advertindo que devam ser entendidas como modelo, já que $n$ muda com o período, enquanto que $\varepsilon$ permanece constante para um intervalo grande de períodos, num dielétrico homogêneo. Informou a concordância da relação para gases, citando Boltzmann, e também para hidrocarbonetos líquidos. Indicou a discrepância para vidros e líquidos como água e álcool, remetendo tais questões à dispersão. Discutiu o caso do enxofre ortorrômbico, a partir dos dados de Boltzmann 88] (para $\varepsilon_{i}$ ) e de A. Schrauf (para $n_{i}$ ), onde $\varepsilon_{i} \approx n_{i}^{2}$, sendo as pequenas discrepâncias analisadas à luz da equação de dispersão de Cauchy (35). Em outros cristais indicou que a diferença é mais acentuada, assegurando que as discrepâncias são de mesma natureza que nos meios isotrópicos e devidas à dispersão. No capítulo $\mathrm{V}$, dedicado à dispersão, indicou o desenvolvimento da teoria da dispersão a partir de Cauchy [55], passando por Leroux [77] e tomando a forma padrão à época a partir dos trabalhos de Sellmeier [118] [119, Helmholtz [120], afirmando que adotou em seu livro a abordagem que decorre de Helmholtz. Afirmou que a ideia básica da teoria da dispersão consiste em assumir que as menores partículas de um corpo, as quais são eletricamente carregadas positivamente ou negativamente, conforme "indicado pela eletrólise",16 possuem períodos de vibração naturais. Tais partículas são postas em vibração

\footnotetext{
$\overline{16}$ Aqui Drude não se refere ao elétron de Lorentz, mais ao "elétron eletrolítico", o qual é o próton. Os resultados de Zeeman e de J.J.
}

de maior ou menor intensidade de acordo a afinidade de seus períodos naturais com relação ao período das ondas luminais incidentes. Para obter a equação da dispersão Drude abordou a questão de modo similar ao que fizera Lorentz, através da correção à corrente de deslocamento devido às polarizações induzidas pelo movimento das partículas carregadas do meio, cujo efeito prático é produzir uma permeabilidade efetiva. Chegou assim à expressão para meios transparentes

$$
\varepsilon^{\prime}=n^{2}=1+\sum_{k} \frac{\vartheta_{k}^{\prime}}{1-b_{k} / T^{2}} .
$$

A permissividade usual $\varepsilon$ do meio é aquela para "longos períodos", $\varepsilon=\varepsilon^{\prime}(\infty)$, a qual pode ser entendida como a constante dielétrica do éter livre acrescida da contribuição resultante da soma de todos os "tipos de íons". Após separar os períodos característicos do infravermelho ao ultravioleta, resulta da expressão anterior que

$$
\varepsilon^{\prime}=n^{2}=-A^{\prime} T^{2}+A+\frac{B}{T^{2}}+\frac{C}{T^{4}},
$$

sendo todas as constantes $\left(A^{\prime}, A, B, C\right)$ positivas. O termo $A^{\prime}$, porém, somente se torna relevante para períodos característicos do infravermelho, o que está em estreita correspondência com o comportamento da água. Afirmou também que os dados para vidro flint, cristais de quartzo, halita, silvina e fluorita confirmam quantitativamente a equação de dispersão (81) para comprimentos de onda longos. A primeira edição em língua inglesa do livro de Drude surgiu em 1902, intitulado "Theory of Optics" [121. No prefácio, Albert Abraham Michelson (1852-1931) o apontou como o primeiro livro em língua inglesa a fornecer a fundamentação eletromagnética apropriada para uma teoria ondulatória da luz,
"escrito por quem tem contribuído tão lar- gamente ao progresso que se tem feito na Óptica nos últimos dez anos." [121, p. iv]

Retrospectivamente está claro que o entendimento da estrutura da matéria, à época da publicação do livro de Drude e da teoria do elétron de Lorentz, e portanto anterior mecânica quântica, era insipiente. Mas as discrepâncias experimentais entre $\varepsilon$ e $n$ já encontravam aí um arcabouço teórico capaz de dar-lhes um significado em harmonia com a teoria eletromagnética da luz. No prefácio Drude afirmou
"a teoria eletromagnética está analiti- camente em completo acordo com os fenômenos, mas os valores exatos das constantes ópticas não podem ser obtidas de medidas elétricas. Tais constantes dependem de um modo que não pode ser previsto da cor da luz." [121, p. vi]

Thomson para $e / m$ já indicavam, no entanto, que não se tratava do mesmo objeto. 
Demos ao leitor a impressão de que tudo estava consumado em favor da teoria eletromagnética da luz, no alvorecer do século $X X$. Porém, em 1904, William Thomson, agora "lord Kelvin", publicou suas "Baltimore Lectures" 122. No prefácio, Kelvin afirmou que adotaria a perspectiva de explorar ao limite as possibilidades da teoria elástica da luz em um éter do tipo sólido elástico, ciente de que era insuficiente. A insuficiência se revelava, diz ele, nos fenômenos magnéticos. Acrescentou então que "a-assim chamada - "teoria eletromagnética da luz" tampouco nos ajudou". O problema central estava, para ele, na impossibilidade de reconciliar a corrente de deslocamento com uma visão mecânica subjacente, o que o levou a considerar a teoria eletromagnética da luz um "passo atrás". Uma errata, de 1906, nada modificou de suas considerações sobre a teoria eletromagnética da luz. Kelvin, que morreu em 1907, mostrou-se afinal avesso à ideia de que a teoria eletromagnética fosse o fundamento da teoria ondulatória da luz.

Também em 1904 surgiu o livro de Arthur Schuster 123. No prefácio vemos que a objeção à corrente de deslocamento não era apanágio exclusivo de Kelvin. Schuster afirma que

"não há no presente teoria da óptica no sentido em que a teoria do sólido elástico era aceita a cinquenta anos atrás. Abandonamos aquela teoria e aprendemos que as ondulações da luz são ondas eletromagnéticas." Mas pondera que "enquanto o caráter dos deslocamentos que constitui tais ondas permanece indefinido não podemos ter a pretensão de ter estabelecido uma teoria da luz". [123, p. v]

Adverte então seu leitor sobre o tipo de mentalidade que se formou entre os físicos, sobre o sentido e a finalidade da descrição dos fenômenos naturais, que

\begin{abstract}
"[...] devem olhar com a mais grave preocupação a crescente escola de pensamento científico que se contenta com equações que representam corretamente as relações numéricas entre diferentes fenômenos, mesmo que um sentido preciso não possa ser atribuído aos símbolos usados. O fato de que tal escola filosófica evasiva tenha recebido algum apoio dos escritos de Heinrich Hertz torna ainda mais necessário que seja tratada com seriedade e resistida vigorosamente."
\end{abstract} [123, p. v]

Admitiu que as equações eletromagnéticas prestaram valiosa contribuição ao debate, mas que são uma "ferramenta" para se alcançar uma teoria mais completa. Explicitou então sua posição dentro deste embate epistemológico:

"O estudo da Física deve ser baseado no conhecimento da Mecânica, e o problema da luz somente será resolvido quando tivermos descoberto as propriedades mecânicas do éter. Enquanto permanecermos ignorantes sobre o assunto fundamental concernente à origem das deformações e tensões elétrica $e$ magnética, é necessário introduzir o estudo teórico da luz por um tratamento cuidadoso da propagação da onda através de meios cujas propriedades elásticas são conhecidas. Um estudo da teoria do som e da antiga teoria do sólido elástico da luz deve preceder portanto a introdução das equações eletromagnéticas." [123, p. vi]

Tomamos aqui as opiniões de Kelvin e Schuster como emblemáticas do "espírito de uma época", como membros qualificados da comunidade de físicos que eram, e que compreendiam aquilo que afirmava - e omitia - a teoria eletromagnética da luz. A resenha da Nature [124] ao livro de Schuster, de março de 1905, não poupou elogios ao ressaltar o "excelente serviço prestado à professores e estudantes com a publicaçẫo do livro" e novamente repercutiu o dilema apontado por Schuster entre a escola mecanicista e a outra que qualificou de "evasiva", elogiando a admirável lucidez do autor. O advento subsequente da teoria da relatividade especial trouxe novos e impactantes desenvolvimentos, os quais contribuíram para tornar esse debate específico obsoleto, na medida em que tornou o próprio éter luminífero obsoleto.

\section{Conclusão}

Procuramos evidenciar, neste artigo, como as características básicas da teoria da birrefringência, conforme elaborada por Fresnel, sobreviveram essencialmente incólumes até os nossos dias. A ideia radical da transversalidade não encontrou apoio nos antecessores de Fresnel, mas o tornou capaz de elaborar um sofisticado mecanismo pelo qual o meio anisotrópico seleciona os modos de polarização, esclarecendo a razão da não interferência de dois raios polarizados perpendicularmente um ao outro, e ainda assim, na passagem sucessiva por mais de um corpo anisotrópico, ser capaz de produzir cores, como nos fenômenos de polarização cromática, caracterizando os modos de polarização linear, circular e elíptico em seu sentido atual.

Suas especulações acerca da natureza elástica da onda luminosa inspirou o desenvolvimento de uma elastodinâmica da luz que, dominou o desenvolvimento da óptica teórica por 80 anos, e que, ironicamente, pareceu mais desajustar-se do que ajustar-se ao esquema originalmente proposto por Fresnel, como aqui ilustramos através da discussão da primeira teoria de Green.

A postulação, por Maxwell de uma teoria eletromagnética da luz trouxe para a nova teoria o ônus natural de ser capaz de construir com ela uma teoria da birrefringência. Aqui, a teoria da birrefringência de Fresnel serviu de guia e de filtro para a depuração de Maxwell, 
em relação às suas próprias equações eletromagnéticas, as quais precisavam produzir ondas puramente transversais nas condições apropriadas à descrição da óptica dos meios cristalinos. Apontamos aqui a ambivalência de Maxwell em realizar plenamente este objetivo por seu apego ao potencial vetorial magnético, problema esse cuja superação foi indicada por ele em seus últimos escritos, mas que somente ficaria bem estabelecido pelas mãos de seus sucessores, a exemplo de Heaviside. O preço para a teoria eletromagnética foi o de afastar-se de uma correspondência direta com as tensões e movimentos do éter. O ganho, para além do sentido maior da unificação encarnada nas equações de Maxwell, foi o de ajustar-se perfeitamente à teoria da birrefringência de Fresnel.

A dificuldade residual ligou-se à dispersão e absorção, que tampouco fora considerada por Fresnel em sua formulação original, mas que se configurava para ele, já em 1825, como o grande desafio subsequente no desenvolvimento da óptica teórica. Tal desafio somente pôde ser devidamente confrontado na última década do século XIX com o advento do elétron, para além da própria teoria eletromagnética da luz em sua formulação original. Nos leva a pensar sobre quais rumos teria Fresnel dado à teoria da dispersão, tivesse ele vivido para poder realizá-la.

Nesse ano de 2021 a obra de Fresnel, particularmente sua teoria da birrefringência, permanece uma das sólidas edificações da física, de valor atemporal.

\section{Referências}

[1] A.J. Fresnel, em: Oeuvres Compètes (Imprimerie impériale, Paris, 1868), t. 1, p. 89.

[2] T. Young, Philosophical Transactions of Royal Society 92, 12 (1802).

[3] T. Young, Philosophical Transactions of Royal Society 92, 387 (1802).

[4] T. Young, Philosophical Transactions of Royal Society 94, 1 (1804).

[5] E. Malus, em: Nouveau Bulletin des Sciences par la Société Philomathique de Paris (Bernard, Paris, 1809), t. 1 , p. 266.

[6] E. Malus, em: Mémoires de Physique et de Chimie de la Société d'Arcueil (Bernard, Paris, 1809), t. 2, p. 254.

[7] E. Malus, em: Nouveau Bulletin des Sciences par la Société Philomathique de Paris (Bernard, Paris, 1809), t. 1 , p. 341.

[8] E. Malus, em: Mémoires Présentés a l'Institut des Sciences par Divers Savants (Boudouin, Paris, 1811), v. 2, p. 303 .

[9] E. Malus, em: Mémoires de la Classe des Sciences Mathématique et Physiques de l'Institut Impérial de France (Firmin Didot, Paris, 1814), t. 11, p. 105.

[10] E. Malus, em: Mémoires de la Classe des Sciences Mathématique et Physiques de l'Institut Impérial de France (Firmin Didot, Paris, 1814), t. 11, p. 112.
[11] F. Arago, em: Mémoires de la classe des Sciences Mathématique et Physiques de l'Institut Impérial de France (Firmin Didot, Paris, 1812), t. 1, p. 93.

[12] A.J. Fresnel, em: Oeuvres Complètes (Imprimerie impériale, Paris, 1866) t. 1, p. 247.

[13] R.H. Silliman, em: Dicionário de Biografias Científicas, editado por C. Benjamin (Contraponto, Rio de Janeiro, 2007), v. 1, p. 860.

[14] C. Huygens, Cadernos de História e Filosofia da Ciência 1, 1 (1986).

[15] J.B. Biot, em: Mémoires de la Classe des Sciences Mathématique et Physiques de l'Institut Impérial de France (Firmin Didot, Paris, 1812), t. 1, p. 135.

[16] J.B. Biot, em: Mémoires de la Classe des Sciences Mathématique et Physiques de l'Institut Impérial de France (Firmin Didot, Paris, 1814), t. 1, p. 1.

[17] J.B. Biot, em: Mémoires de l'Académie Royale des Sciences (Firmin Didot, Paris, 1819), t. 2, p. 41.

[18] J.B. Biot, em: Annales de Chimie et de Physique (Crochard, Paris, 1818), t. 9, p. 372

[19] J.B. Biot, em: Annales de Chimie et de Physique (Crochard, Paris, 1819), t. 10, p. 63.

[20] T. Young, Quaterly Review 11, 42 (1814).

[21] A.J. Fresnel, em: Oeuvres Complètes (Imprimerie impériale, Paris, 1866), t. 1, p. 385.

[22] T. Young, em: Miscellaneous Works (George Peacock, London, 1855), p. 279.

[23] A.J. Fresnel e F. Arago, em: Oeuvres Complètes (Imprimerie impériale, Paris, 1866), t. 1, p. 509.

[24] A.J. Fresnel, em: Oeuvres Complètes (Imprimerie impériale, Paris, 1866), t. 1, p. 609.

[25] J.Z. Buchwald, The Rise of the Wave Theory of Light (Chicago University Press, Chicago, 1989).

[26] D. Brewster, Philosophical Transactions of Royal Society 108, 199 (1818).

[27] A.J. Fresnel, em: Oeuvres Complètes (Imprimerie impériale, Paris, 1868), t. 2, p. 465.

[28] A.J. Fresnel, em: Oeuvres Complètes (Imprimerie impériale, Paris, 1868), t. 2, p.331.

[29] M. Born e E. Wolf, Principles of Optics (Cambridge University Press, Cambridge, 1999), 7 ed.

[30] A.J. Fresnel, em: Oeuvres Complètes (Imprimerie impériale, Paris, 1868), t. 2, p. 261.

[31] A.J. Fresnel, em: Oeuvres Complètes (Imprimerie impériale, Paris, 1868), t. 2, p. 309.

[32] A.J. Fresnel, em: Oeuvres Complètes (Imprimerie impériale, Paris, 1868), t. 2, p. 343.

[33] A.J. Fresnel, em: Oeuvres Complètes (Imprimerie impériale, Paris, 1868), t. 2, p. 369.

[34] A.J. Fresnel, em: Oeuvres Complètes (Imprimerie impériale, Paris, 1866), t. 1.

[35] A.J. Fresnel, em: Oeuvres Complètes (Imprimerie impériale, Paris, 1868), t. 2, p. 326.

[36] O. Darrigol, A history of Optics - From Greek Antiquity to the Nineteenth Century (Oxford University Press, Oxford, 2012).

[37] A.J. Fresnel, em: Oeuvres Complètes (Imprimerie impériale, Paris, 1866), t. 1, p. 719. 
[38] A.J. Fresnel, em: Oeuvres Complètes (Imprimerie impériale, Paris, 1868), t. 2, p. 479.

[39] A.J. Fresnel, em: Oeuvres Complètes (Imprimerie impériale, Paris, 1868), t. 2, p. 3.

[40] C. Navier, em: Mémoire de l'Academie des Sciences (Firmin Didot, Paris, 1827), t. 7, p. 375.

[41] A. Cauchy, Exercices de Mathématiques (Bure Frères, Paris, 1827), v. 2, p. 42.

[42] A. Cauchy, Exercices de Mathématiques (Bure Frères, Paris, 1828), v. 3, p. 160.

[43] A. Cauchy, Exercices de Mathématiques (Bure Frères, Paris, 1828), v. 3, p. 188

[44] E.T. Whittaker, History of the theories of aether and electricity - the Classical Theories (Thomas Nelson and Sons, London, 1951).

[45] F.E. Neumann, Annallen der Physik 101, 418 (1832).

[46] J. MacCullagh, Transactions of the Royal Irish Academy 21, 17 (1848).

[47] J. MacCullagh, Philosophical Magazine Series 3 10, 42 (1837).

[48] G. Green, Transactions of the Cambridge Philosophical Society 7, 1 (1838).

[49] G. Green, Transactions of the Cambridge Philosophical Society 7, 121 (1839).

[50] A. Cauchy, em: Mémoire de l'Academie des Sciences (Firmin Didot, Paris, 1831), t. 10, p. 293.

[51] M.C. Lima e L. Silva, Revista Brasileira de Ensino de Física 41, e20180264 (2019).

[52] A. Cauchy, Bulletin des Sciences Mathematiques, Physiques et Chimique 14, 6 (1830).

[53] A. Cauchy, Comptes Rendus 2, 341 (1836).

[54] A. Cauchy, em: Mémoire de l'Academie des Sciences (Firmin Didot, Paris, 1842), t. 18, p. 153.

[55] A. Cauchy, Nouveaux Exercices de Mathématiques (J.G. Calve, Prague, 1836).

[56] G.N. Cantor e M.J.S. Hodge, Conceptions of ether (Cabridge University Press, Cambridge, 1981)

[57] L.D. Landau e E.M. Lifschiz, Theory of elasticity (Pergamon Press, Oxford, 1959).

[58] A. Cauchy, Comptes Rendus 9, 676 (1839).

[59] W. Thomson, Philosophical Magagazine 26, 414 (1888).

[60] G. Green, em: Mathematical Papers (MacMillan and Co., London, 1871), p. 1.

[61] M. Faraday, Experimental Reseaches in Electricity (Cambridge University Press, Cambridge, 2012).

[62] W. Thomson, Cambridge Mathematical Journal 3, 71 (1843).

[63] W. Thomson, Cambrigde and Dublin Mathematical Journal 1, 75 (1845).

[64] W. Thomson, Cambridge and Dublin Mathematical Journal 2, 61 (1847).

[65] W. Thomson, Philosophical Magazine Series 4 1, 177 (1851).

[66] W. Thomson, Philosophical Transactions of Royal Society 141, 243 (1851)

[67] W. Thomson, Proceedings of Royal Society 8, 150 (1857).
[68] J.C. Maxwell, em: The Scientific Papers of James Clerk Maxwell (Dover, New York, 1965), v. 1, p. 451.

[69] W. Weber e R. Kohlrausch, Revista Brasileira de História da Ciência 1, 94 (2008)

[70] O. Darrigol, Electrodynamics from Ampère to Einstein (Oxford University Press, Oxford, 2000)

[71] J.C. Maxwell, em: The Scientific Papers of James Clerk Maxwell (Dover, New York, 1965), v. 1, p. 526

[72] M. Faraday, Philosophical Transactions 139, 1 (1849).

[73] J. Plücker, Philosophical Magazine 34, 450 (1849).

[74] H. Knoblauch, Philosophical Magazine 2, 33 (1851)

[75] J.C. Maxwell, A treatise on electricity and magnetism (Clarendon Press, Oxford, 1873), v. 2.

[76] J.C. Gibson e T. Barclay, Philosophical Transactions of Royal Society 161, 573 (1871).

[77] M.F.P. Leroux, Comptes Rendus 55, 126 (1862).

[78] Rayleigh, Philosophical Magazine 48, 151 (1899).

[79] G.G. Stokes, em: Report of the British Association for the Advancement of Science (Taylor and Francis, London, 1863), p. 253.

[80] H. Helmholtz, Journal fur die Reine und Angewandte Mathematik 72, 57 (1870).

[81] H. Helmholtz, Philosophical Magazine 44, 530 (1872).

[82] H. Helmholtz, Journal fur die Reine und Angewandte Mathematik 75, 35 (1873)

[83] H. Helmholtz, Journal fur die Reine und Angewandte Mathematik 78, 273 (1874).

[84] H. Hertz, Electric Waves (Dover, New York, 1962).

[85] J.Z. Buchwald, The creation of scientific effects: Heinrich Hertz and electric waves (University of Chicago Press, Chicago, 1994)

[86] L. Boltzmann, Wiener Berichte 69, 795 (1874).

[87] L. Boltzmann, Annalen der Physik und Chemie 155, 403 (1875).

[88] L. Boltzmann, Wiener Berichte 70, 342 (1874).

[89] E. Hecht, Optics (Addison Wesley, San Francisco, 2002), 4 ed.

[90] J.C. Maxwell, A treatise on electricity and magnetism (Clarendon Press, Oxford, 1881), v. 2, 2 ed.

[91] J. Hopkinson, Proceedings of the Royal Society 25, 496 (1877).

[92] J. Hopkinson, Proceedings of the Royal Society 31, 148 (1881).

[93] J. Hopkinson, Proceedings of the Royal Society 31, 347 (1881).

[94] J.C. Maxwell, Traité d'Électricité et de Magnétisme (Gauthier-Villars, Paris, 1885), t. 1

[95] J.C. Maxwell, Traité d'Électricité et de Magnétisme, (Gauthier-Villars, Paris, 1885), t. 2.

[96] O. Heaviside, Electrical Papers (MacMillan and Co., London, 1892), v. 1, p. 429

[97] O. Heaviside, Electrical Papers (MacMillan and Co., London, 1894), v.2, p. 39

[98] H. Hertz, Annalen der Physik und Chemie 23, 84 (1884).

[99] B.J. Hunt, Os seguidores de Maxwell (Editora UFMG, Belo Horizonte, 2015). 
[100] H. Poincaré, Électricité et Optique I - Les théories de Maxwell et laa théorie electromagnétique de la Lumière (G. Carré, Paris, 1890).

[101] L.G. Gouy, Comptes Rendus 106, 540 (1888).

[102] J. Curie, La Lumière électrique 29, 127 (1888).

[103] H. Poincaré, Électricité et Optique II - Les théories de Helmholtz et les expériences de Hertz (G. Carré, Paris, 1891).

[104] J.C. Maxwell, A treatise on electricity and magnetism (Clarendon Press, Oxford, 1892), v. 2, 3 ed.

[105] J.J. Thomson, Proceedings of Royal Society 44, 292 (1890).

[106] R. Blondlot, Comptes Rendus 112, 1058 (1891).

[107] E. Lecher, Annalen der Physik 278, 142 (1890).

[108] J.J. Thomson, Notes on Recent Researches in Electricity and Magnetism (Clarendon Press, Oxford, 1893).

[109] J.J. Thomson, Philosophical Magazine 30, 129 (1890).

[110] L. Arons e H. Rubens, Annalen Der Physik 278, 581 (1891).

[111] L. Arons e H. Rubens, Annalen Der Physik 280, 206 (1891).

[112] O. Heaviside, Electromagnetic Theory (The Electrician Printing and Publishing Co., London, 1894), v. 1.

[113] H.A. Lorentz, em: Collected Papers (Springer, Dordrecht, 1936), v. 2, p. 164.

[114] H.A. Lorentz, em: Collected Papers (Springer, Dordrecht, 1937), v. 5, p. 1.

[115] J.J. Thomson, Philosophical Magazine 44, 293 (1897).

[116] J.J. Thomson, Philosophical Magazine 48, 547 (1899).

[117] P. Drude, Lehrbuch der Optik (S. Hirzel, Leipzig, 1900).

[118] W. Sellmeier, Annalen der Physik 223, 386 (1872).

[119] W. Sellmeier, Annalen der Physik 223, 525 (1872).

[120] H. Helmholtz, Annalen der Physik 230, 582 (1875).

[121] P. Drude, Theory of optics (Longmans, Green and Co., New York, 1902).

[122] W. Thomson, Baltimore Lectures on molecular dynamics and the wave theory of light (C.J. Clay and Sons-Cambridge University Press, London, 1904).

[123] A. Schuster, An introduction to the Theory of Optics (Edward Arnold, London, 1904).

[124] Nature 71, 457 (1905). 